\title{
On the sunk-cost effect in economic decision-making: a meta-analytic review
}

\author{
Stefan Roth • Thomas Robbert • Lennart Straus
}

Received: 30 April 2013/Accepted: 25 August 2014/Published online: 19 September 2014

(C) The Author(s) 2014. This article is published with open access at Springerlink.com

\begin{abstract}
Although the effect of monetary sunk costs on decision-making is widely discussed, research is still fragmented, and results are sometimes controversial. One reason for this incomplete picture is the missing differentiation between the effect of sunk costs on utilization and progress decisions and its respective moderators. This article presents the results of a meta-analytic review of 98 effect sizes of the sunk-cost effect, with special emphasis on the decision-specific influence of moderators. The results show clear evidence that the sunk-cost effect emerges, though its effect size and the influence of the moderators are contingent on the respective decision type. In particular, we find support for the idea that the sunkcost effect is attenuated by time in utilization decisions. The results also reveal that older adults are less likely to fall prey to the sunk-cost effect than younger adults.
\end{abstract}

Keywords Sunk-cost effect · Meta-analytic review · Utilization decision · Progress decision - Escalation of commitment

JEL Classification D11 - D80

Responsible editor: Sönke Albers (Marketing).

Electronic supplementary material The online version of this article (doi:10.1007/s40685-014-0014-8) contains supplementary material, which is available to authorized users.

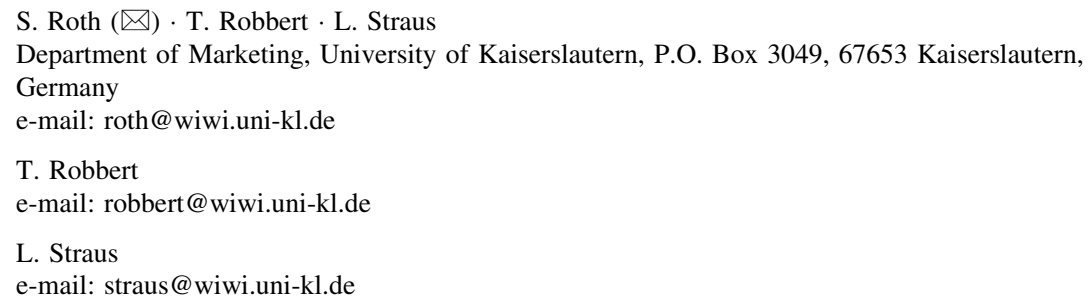




\section{Introduction}

Examples of the impact of sunk costs on decision-making appear not only in corporate decision-making but in everyday decisions as well. For example, imagine that you bought a ticket for a play at your local theater. A couple of days later, a good friend calls and invites you to a special Italian dinner the evening of the play. Although you would prefer to attend the dinner, your thoughts revolve around the sunk cost of the already-paid-for theater ticket, and you decide to attend the play. Examples of the impact of sunk costs on corporate decisions include R\&D investments, such as the development of the supersonic plane Concorde. Already in early development stages, the plane was significantly more expensive than expected, and the financial success of the project was unclear. However, the project was not stopped, and new funds were allocated to finish the plane on the grounds that the large amount of money that has already been invested should not have been wasted (Arkes and Ayton 1999, p. 591).

At first glance, these two dissimilar decision situations share one core theme: in both situations, irrecoverable money has been invested and "costs are sunk". According to microeconomic theory, people should base their decisions only on current and future benefits and costs. Yet decision-makers sometimes deviate from this basic principle of microeconomic theory and take sunk costs into account. The resulting sunk-cost effect has been examined in a variety of disciplines, including psychology (e.g., Astebro et al. 2007; Strough et al. 2008), sociology (e.g., Janssen et al. 2003), management (e.g., Conlon and Garland 1993; Keil et al. 2000), marketing (e.g., Soman and Cheema 2001; Soman and Gourville 2001), industrial economics (e.g., Manez et al. 2009), and finance (e.g., Guler 2007). As such, the situations in which the sunk-cost effect is observed are also substantially different. Even when we consider economic decisions in which individuals react to past monetary investments, we find only two distinct research streams in academic literature. Therefore, Moon (2001) calls for a clear distinction between utilization and progress decisions. As our first example illustrates, a utilization decision focuses on a decision-maker confronted with the choice between two equally attractive alternatives, such that preferences shift to the sunk-cost alternative. In contrast, our second example highlights a series of progress decisions in which the decision-maker allocates additional resources to an initially chosen alternative, such that sunk costs increase the likelihood of further fund allocation.

In line with this argumentation, it is surprising that academic literature on the sunk-cost effect has not clearly distinguished between these two types of decisions (e.g., Arkes and Blumer 1985). To date, the lack of differentiation combined with the ambiguous definition of the sunk-cost effect does not allow for comparability or generalization of the respective findings. There is neither a comprehensive review that elaborates on different effect sizes nor, and more important, a review that examines possible moderators of the effect for both decisions. In addition, research on both types often elaborates on net effects that may be influenced by other factors rather than a sunk-cost effect per se. This makes the findings even less comparable. Thus, it is not surprising to observe controversial findings on the existence, 
moderators, and underlying causes of the sunk-cost effect (Staw 1976; Thaler 1980; Arkes and Blumer 1985; Ashraf et al. 2010).

The current research strives to fill this gap by presenting the results of a metaanalytic review on the influence of possible moderators on the effect of monetary sunk costs. Although we expect the influence of sunk costs to vary between utilization and progress decisions, we also argue that the moderators differ in their impact on the effect. Consequently, the main objective of this article is to systematically analyze factors that influence the effect of sunk costs on economic decision-making with regard to utilization and progress decisions. Therefore, we tackle the challenging task of summarizing the findings for each decision type, while keeping the broader picture of the impact of sunk costs on economic decisionmaking in mind.

To attain that goal, we systematically review the existing literature, covering a period from 1976 to 2013. We analyze the findings in a meta-analytic review to summarize, integrate, and interpret prior results. Specifically, we are the first to clearly classify each data set in each study as either a utilization or a progress decision. Thereafter, we investigate two sets of variables: (1) we elaborate on two hypothesized moderators-namely, familiarity with economic decision-making and time delay - and (2) we include other variables such as study and research design descriptors (e.g., region, age), which typically appear in meta-analytic reviews to control for study-specific factors. Our goal is to shed light on why some research results are not conclusive and to provide guidance on the factors that actually increase or decrease the sunk-cost effect in utilization and progress decisions. We contribute to existing literature with the following key findings:

- We estimate the effect size of the sunk-cost effect with respect to the two different decision types and show clear evidence for the sunk-cost effect.

- We find support for the idea that time in utilization decisions attenuates the sunk-cost effect.

- We find that the impact of sunk costs is particularly high when individuals are young or students.

- Surprisingly, our results do not support the notion that high familiarity with economic decision-making, such as economic education, can effectively reduce the sunk-cost effect.

The remainder of this article proceeds as follows: first, we present existing definitions of the sunk-cost effect, thereby clarifying the differences and commonalities of the effect in progress and utilization decisions. Second, we separately present empirical evidence of the sunk-cost effect for each decision type. Third, we derive hypotheses on the effect of sunk costs on economic decision-making and the impact of possible moderators. Fourth, we present the procedure of our metaanalytic review and discuss the findings separately for both decision types. Finally, we provide potential reasons for converging or contradicting outcomes and elaborate on managerial consequences. We conclude by presenting avenues for further research. 


\section{Definition and delineation}

Past costs and benefits are irrecoverable and should not affect current or future decisions (Heath 1995: 38). Yet Thaler (1980) argues that consumers do not ignore sunk costs in their everyday decisions and thus fail to make correct decisions. Rather, consumers are influenced by past decisions and past expenditures. Thaler (1980: 47) refers to the influence of already spent money on decisions as the sunkcost effect and argues that "paying for the right to use a good or service will increase the rate at which the good will be utilized, ceteris paribus." However, this explanation only addresses one kind of situation in which the sunk-cost effect occurs. To overcome this shortcoming, Arkes and Blumer (1985: 124) define the sunk-cost effect as "a greater tendency to continue an endeavor once an investment in money, effort, or time has been made." In line with this, management literature examines a related behavior under the label of escalation of commitment. In line with the definition of Brockner (1992), escalation of commitment refers to the tendency for decision-makers to persist with a failing course of action. As a pioneer, Staw (1976) demonstrates that decision-makers escalate their commitment by allocating additional resources to an initially chosen project. Literature offers a variety of factors that foster the escalation of commitment, including the justification of previous decisions and the desire not to appear wasteful (Staw 1976, 1981; Arkes and Blumer 1985; Garland and Newport 1991; Brockner 1992; Schaubroeck and Davis 1994; Tan and Yates 1995). The sunk-cost effect is considered just one driver of this escalation tendency (Sleesman et al. 2012). Some researchers argue that the sunk-cost effect has often been confounded and confused with other effects, such as the project completion effect (Garland and Newport 1991; Conlon and Garland 1993; Garland and Conlon 1998; Boehne and Paese 2000; Jensen et al. 2011). In addition to the reasoning with behavioral mechanisms, some researchers argue that such biases are due to informational asymmetries or inefficiencies (Shin 2008; Simester and Zhang 2010).

Thus, by discussing the effect of sunk costs on escalation tendencies and utilization decisions at the same time and in an interchangeable manner, literature compares apples and oranges. Garland and Conlon (1998) and subsequently Moon (2001) call for a distinction between these two kinds of decisions when elaborating on the sunk-cost effect: utilization and progress decisions.

Utilization decisions focus either on the choice between similar attractive alternatives with different levels of sunk costs or on the usage intensity of an already-paid-for product. In the first case, the decision-maker purchases a good or service for which the costs, which are greater than zero, incur instantly and are nonrefundable. However, before actually consuming the good or service, the decisionmaker is confronted with an additional but similar attractive alternative that is offered at lower or no cost. This alternative can also be the non-utilization of the initially purchased good or service. In any case, the sunk costs are higher for the first alternative. Subsequently, the decision-maker must decide on the utilization of one of the two alternatives. It is impossible to use both. In addition, preferences of the decision-maker may have changed; they can be in favor of both or in favor of just one alternative. A sunk-cost effect arises whenever the decision-maker has equal 
preferences for both alternatives or even prefers the second alternative, but decides in favor of the alternative with the higher level of sunk costs. In the second case, the decision-maker also purchases a good or service and costs are sunk. The actual decision, however, pertains to the utilization intensity of this paid-for product. Therefore, the sunk-cost effect describes the usage of this good or service beyond the point that marginal utility decision models would predict. Nevertheless, in both cases the full price for the product is paid, the costs are sunk, and the consumer must decide whether to exploit their utility.

Progress decisions imply that the decision-maker decides to start a project with an initial investment. Therefore, he or she allocates resources subsequently tied to the project. At a later stage of the project, the decision-maker receives new projectrelated information that was not accessible at the start. As a result, he or she must decide on the continuation of the project, which involves the investment of additional resources. Without these additional funds, the project will be abandoned, which results in an irrecoverable loss of all resources already invested in the project. Whenever a decision-maker persists in continuing an initially chosen but failing course of action, this phenomenon is referred to as escalation of commitment.

In the following, we use two criteria to categorize the two decision types:

(1) Further investments In progress decisions, the benefits of the project can only be realized by finishing the project successfully. The decision-maker must decide on the continuation of the project. In the extreme, this results in an irrecoverable loss of all resources that have already been invested in the project in the case of cancelation. However, at least the end result might still be positive, but less so than some other better alternative. In contrast, the benefits of a paid product can be exploited without further monetary investments by making use of the product.

(2) Status of the investment Progress decisions are context specific, in that they depend on the status of the project. The full benefits from the investment are still pending and contingent on the successful completion of the project. In contrast, in utilization decisions a product is paid and the benefits can be immediately derived through usage.

\section{Empirical evidence}

Empirical evidence on the sunk-cost effect is diverse. We present only the findings of the effect of monetary investments on individual decision-making, thereby accounting for the decision type and the hypothesized moderators of each study.

With regard to utilization decisions, Arkes and Blumer (1985) ask their participants to choose between two differently priced but already-paid-for ski trips that coincidentally take place on the same weekend. Despite a stimulated preference for the cheaper ski trip, their results indicate that higher sunk costs for one of the alternatives significantly increased its consumption likelihood. Thaler (1980) and Gourville and Soman (1998) present similar results; their participants had to decide either to brave a snowstorm to attend a paid basketball game or to watch the game at 
home. In a similar vein, research has shown the increased preference for the sunkcost alternative for differently priced summer holidays (Tan and Yates 1995) and theater tickets (Soman 2001). Robbert (2013) examines the sunk-cost effect in an experimental card game with differently priced cards and reveals that sunk costs affect participants' gambling behavior. Just and Wansink (2011) manipulate the fee of a buffet at an all-you-can-eat pizza restaurant in their field study. They find that participants who paid the full price for the buffet consumed more slices of pizza than those who paid half the price. Despite these findings, some authors doubt the strength of the effect. In a large field experiment, Ashraf et al. (2010) sold a water purification solution to households in Zambia. They manipulated the product prices and measured the usage intensity of the product without any evidence of an influence of sunk costs on consumption.

In addition to the evidence for the main effect, research elaborates on influential factors such as the decision-maker's familiarity with economic decision-making or the time delay between the initial and the subsequent decision. Greitemeyer et al. (2005) survey bank employees on a utilization decision for an already-paid-for vacation. They find that even employees trained in economic decision-making exhibited the sunk-cost effect. In a similar vein, participants in Tan and Yates's (1995) vacation scenario fell prey to the sunk-cost fallacy, regardless of their background. Gourville and Soman (1998) consider economic exchanges in which they manipulate the temporal separation between the initial and subsequent decision. Measuring the attendance at a basketball game, they find that game attendance was the highest proximate to the payment. Dick and Lord (1998) measure the impact of membership fees on usage intensity over time and also find evidence for the moderating impact of time on the sunk-cost effect. Specifically, they find that higher fees led to an increased number of rentals and that participants psychologically amortized the membership fees over time.

With regard to progress decisions, Garland (1990) shows a positive and linear relationship between participants' willingness to allocate additional resources to an ongoing project and the proportion of the already-expended budget. Vetter et al. (2012) reveal that sunk costs have a reinforcing impact on the decision-maker's propensity to maintain previously made IT-outsourcing decisions. In contrast to these findings, most participants in Friedman et al.'s (2007) computer-based treasure hunt game made rational economic decisions. In this game, participants visited different islands on their quest for treasures. Sailing to islands and digging for treasures involved sunk costs, which lowered participants' constrained budget. When they had to decide whether to keep digging or leave the island, they surprisingly ignored the magnitude of their sunk costs for traveling to the respective island.

With regard to the influence of familiarity with economic decision-making, Garland et al. (1990) find that decision-makers familiar with the decision context did not exhibit a sunk-cost effect at all. Fennema and Perkins (2008) also argue that education plays an integral role. They examine the moderating effects of academic training, financial expertise, and decision justification involving sunk costs on the decision to continue a real estate project or not. Comparing the decisions of MBA students and certified public accountants with the decisions of psychology students, 
they show that trained individuals made better decisions. Staw and Fox (1977) examine the impact of a temporal separation of multiple progress decisions in a business case study. Surprisingly, the invested amount of resources did not steadily decline with time, but varied in the way participants invested significant larger financial resources in the third decision than in the second. However, the effect did not diminish with time.

\section{Hypotheses development}

Building on the delineation between the two decision types, we present hypotheses for the main effect and possible moderators. For the main effect, we first develop hypotheses for the sunk-cost effect and then derive hypotheses for the sunk-cost effect in utilization and progress decisions separately. However, our emphasis is on the development of hypotheses for possible moderators and their decision-specific impact on the sunk-cost effect. To develop our hypotheses, we build on Kahneman and Tversky's (1979) prospect theory and Thaler's (1980, 1985, 1999) theory of mental accounting. In addition, Festinger's (1957) theory of cognitive dissonance provides a valuable framework. Table 1 provides a summary of the hypotheses, their theoretical foundation, and empirical evidence.

\subsection{Main effect}

Thaler $(1980,1985,1999)$ builds on prospect theory's (Kahneman and Tversky 1979) ideas and argues that individuals use mental accounts to organize, evaluate, and keep track of their financial activities. Such an account is created after the purchase of a good or service and remains open until the pending benefit is derived through usage. According to Thaler (1980: 49), a loss is felt when a consumer forgoes a pending benefit. In such a case, he or she will have to close the mental account "in the red", experiencing the sunk costs of the transaction as painful. Following this argumentation, the sunk-cost effect in utilization decisions is largely due to the desire of decision-makers not to realize this loss.

The argumentation behind the sunk-cost effect in progress decisions follows a slightly different path, but still builds on prospect theory (Kahneman and Tversky 1979). In line with the shape of the value function, negative values of losses loom larger than positive values of equal gains. Thus, the initial investment of a failing project is overvalued and leads to a subjective loss and the associated negative value. Confronted with the subsequent decision to either depreciate the initial investment or continue to invest, the decision-maker must evaluate the new investment as well. At this decision point, further losses result in a fairly small decrease in value but can result in large increases in value if the investment becomes successful (Arkes and Blumer 1985). Thus, the decision to allocate further resources to an initially chosen course of action is based on a decreasing evaluation of additional losses. Building on these theoretical explanations for the effect of sunk costs on decision-making, we derive the following hypothesis: 


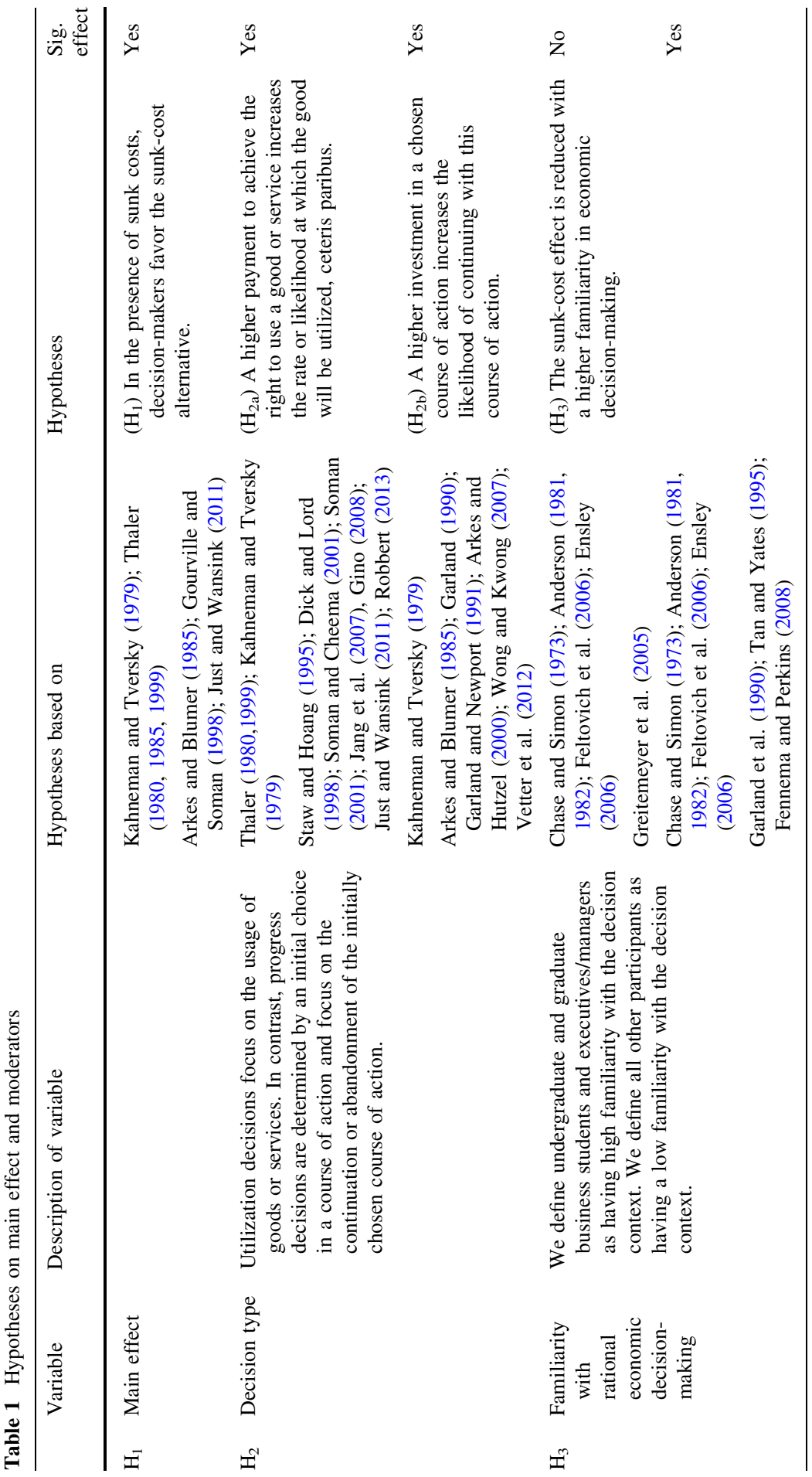




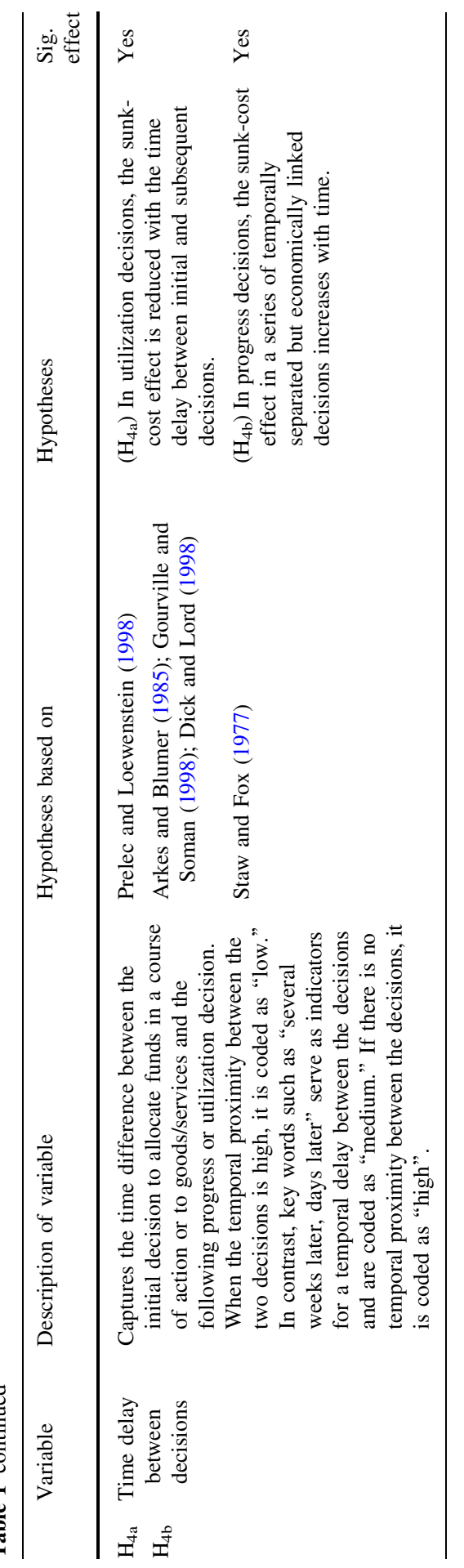


$\mathrm{H}_{1}$ In the presence of sunk costs, decision-makers favor an alternative with higher sunk costs against an alternative with lower or no sunk costs.

We now develop hypotheses on the effect of monetary sunk costs on decisionmaking with respect to the underlying decision situation. First, we focus on the effect in utilizations decisions. To account for these findings, prospect theory's value function states that increasing sunk costs are perceived as a higher loss because the negative psychological value of this loss is also higher (Kahneman and Tversky 1979). Consequently, the psychological pressure of past payments on the future utilization of paid alternatives should increase with the size of this payment (Thaler 1985; Gourville and Soman 1998). Thus, we derive the following hypothesis:

$\mathrm{H}_{2 \mathrm{a}}$ A higher payment to achieve the right to use a good or service increases the rate or likelihood at which the good will be utilized.

Second, we examine the sunk-cost effect in progress decisions. Again, Kahneman and Tversky (1979) argue that decision-makers are likely to view the initial investment as a loss, in which the initial asset position serves as decision-maker's reference point. Withdrawing from this situation would result in a certain realization of this loss. Further investments, however, involve the chance of large increases in value when they become successful. The choice is consequently framed as a withdrawal with a clear loss of sunk costs, versus persistence, with some chance of recovery but a higher chance of additional loss (Garland and Newport 1991). Therefore, we propose the following:

$\mathrm{H}_{2 \mathrm{~b}} \quad$ A higher investment in a chosen course of action increases the likelihood of continuing with this course of action.

\subsection{Hypothesized effects}

Besides the analysis of the main effect of sunk costs on decision-making, we further elaborate on different moderators of the effect. Especially, we focus on decisionmakeŕs familiarity with economic decision-making and the time delay between the initial and subsequent decisions.

\subsubsection{Familiarity with economic decision-making}

One reason individuals might show a sunk-cost effect is that they have never learned about normative principles of economic decision-making. Therefore, one can argue that education and training might be an effective means to reduce the sunk-cost effect. Literature on analogical reasoning and skill acquisition (Chase and Simon 1973; Anderson 1981, 1982) has elaborated on the general association among experts' superior knowledge storage, retrieval abilities, and more accurate problem solving in a specific domain. Moreover, experts differ from novices not only in the access to knowledge, but also with respect to its organization, and they engage in more holistic and conceptual thinking (Feltovich et al. 2006). In addition, experts spend more time trying to understand decision problems. Therefore, they have a 
higher situation awareness, which is based on high familiarization in their domain (Ensley 2006). However, Larkin et al. (1980) argue that the superiority of an expert's skills is limited to his or her area of competence.

Following this line of argumentation, we expect that the impact of familiarity with economic decision-making differs between utilization and progress decisions. Decision-makers are confronted with utilization decisions on an everyday basis. In most cases, the decision-maker might not be aware that he or she is facing an economic decision and consequently does not apply domain-specific knowledge. As a result, he or she falls prey to the sunk-cost effect. In contrast, decision-makers generally are aware of progress decisions' economic character and apply their domain-specific knowledge to solve the problem without displaying a sunk-cost effect. Therefore, we derive the following hypothesis:

$\mathrm{H}_{3}$ The sunk-cost effect is reduced with a higher familiarity in economic decisionmaking.

\subsubsection{Time delay between decisions}

The different characteristics of utilization and progress decisions in the domain of time lead us to derive separate hypotheses for the impact of the time delay between subsequent decisions on the sunk-cost effect. Again, we first focus on utilization decisions. Prelec and Loewenstein (1998) integrate Thaler's (1980, 1985) idea of mental accounts in an evaluation of consumption and payment events. They specify that consumers feel the pain of paying at the time of product purchase, which must be deducted from the pleasure of consumption. Their model comes with two main assumptions: prospective accounting and coupling. Prospective accounting postulates that consumers mentally depreciate past payments, but consider future payments in their full amount. In coupling, individuals create a psychological link between the payment and the consumption of a transaction. In line with their argumentation, coupling moderates the impact of payment on consumption such that the pain of paying attenuates consumption utility and the consumption pleasure buffers the pain of paying. The imputed costs are the highest right after payment and decrease over time. Gourville and Soman (1998) label this gradual adaptation to sunk costs with the passage of time as payment depreciation. Consequently, the sunk-cost effect should be more present in temporal proximity to the payment. Therefore, we propose the following hypothesis:

$\mathrm{H}_{4 \mathrm{a}}$ In utilization decisions, the sunk-cost effect is reduced with the time delay between initial and subsequent decisions.

However, examining this moderator in the context of progress decisions draws a different picture. That is, progress decisions occur in a series of temporally separated but economically linked decisions. In line with this, Staw and Ross (1989) argue that the escalation in response to sunk costs is not created by one initial event but rather by multiple small-impact variables, each insufficient by itself to cause one to remain in a losing situation. Yet, in most projects, there is constant funding over time, and a decline in the project's success may not only make a line of investment 
behavior difficult to extinguish, but also allow the forces that keep the decisionmaker in the series of progress decisions to increase.

In a similar vein, in his theory of cognitive dissonance Festinger (1957) argues that becoming aware that a decision will result in a loss and, thus, a failure implies a negative cognition for decision-makers. The observed persistence eliminates the cognitive dissonance because it enables decision-makers to post hoc rationalize their initial decision (Bazerman et al. 1984). In addition, it offers the (unlikely) opportunity to obtain a satisfying result, thereby also protecting decision-makers' self-esteem. Brockner (1992) labels this as self-justification. In addition, progress decisions are framed as losing situations such that not completing the project leads to an inferior result or even a total loss of the invested resources. It is exactly in this situation that Kahneman and Tversky (1979) expect risk-seeking behavior to occur. Thus, we hypothesize the following:

$\mathrm{H}_{4 \mathrm{~b}}$ In progress decisions, the sunk-cost effect in a series of temporally separated but economically linked decisions increases with time.

\section{Methodology}

We conducted a meta-analysis to test our hypotheses because it uses effect size statistics that are "capable of representing the quantitative findings of a set of research studies in a standardized form that permits meaningful numerical comparison and analysis across studies" (Lipsey and Wilson 2001: 5). The analysis was designed in line with Lipsey and Wilson's (2001) proposed procedure.

\subsection{Literature search}

Beginning with a comprehensive review in multiple databases, we searched for scholarly articles that had combinations of the keywords "sunk-cost effect" or "sunk-cost fallacy", as well as for alternative spellings, also in German. We did not search for the keyword "escalation of commitment", because our focus is exclusively on the effect of sunk costs on decision-making. We conducted the search in seven databases in summer 2013 (Business Source Premier, EconBiz, Science Direct, Springer Link, Social Science Research Network, Wiley Online, and WISO). We searched for papers, doctoral theses, conference proceedings, working papers, and monographs. We also conducted a citation search of influential articles (e.g., Thaler 1980; Arkes and Blumer 1985; Moon 2001) to find articles that we had not listed in previous searches. The literature covered a period from 1976 to 2013 and initially included 360 publications. After we accounted for double entries, this list decreased to 297 entries. We analyzed each article with respect to relevance to the sunk-cost effect.

As inclusion criteria, we only considered studies that explicitly manipulated monetary sunk costs as independent variables and examined how sunk costs influence the individual decision behavior with respect to economic activities. Although many of these articles aimed to understand the drivers of the effect in a 
clean environment, some reported net effects which also may be influenced by other factors than sunk costs. This is especially true for research on progress decisions. Because we use the reported net effects to compute effect sizes, the results of our meta-analysis also have to be understood as net effect sizes. We consequently excluded any study that did not include any empirical data (e.g., Arkes and Ayton 1999; Zayer 2007), did not explicitly manipulate monetary sunk costs as an independent variable (e.g., Staw and Hoang 1995; Camerer and Weber 1999; Soman 2003), or included data for which it was not possible to convert them to effect sizes (e.g., Armstrong et al. 1993). We also removed all studies that examined the sunkcost effect in reaction to time or behavioral investments (Soman 2001; Navarro and Fantino 2009; Otto 2010), without providing an hourly exchange rate or wage, from the data set. In addition, some studies included non-human samples (e.g., Maestripieri and Alleva 1991; Arkes and Ayton 1999; Navarro and Fantino 2005; Macaskill and Hackenberg 2012), which were not considered in our analysis. We also excluded all studies analyzing sunk costs with a strategic purpose (e.g., sunk costs as a market entry barrier; Rosenbaum and Lamort 1992) because our focus is on the effect of sunk costs on individual decision behavior and not on corporate strategy. Finally, we eliminated all studies examining sunk costs in a non-economic setting (e.g., marriage paradoxes; Frey and Eichenberger 1996), which does not apply to our research objective. Our extensive search in online sources allowed us to access almost all the literature we identified in our literature search.

After using our inclusion criteria, we retained 45 studies appropriate for metaanalysis. Some studies provided more than one experiment or independent sample, yielding 111 samples. Of these samples, however, we were unable to calculate effect sizes for 11 because of missing data; thus, we ended up with a total sample size of 100 .

\subsection{Coding}

Appendix 1 presents the modular coding protocol that we used to code relevant information of the 44 remaining studies. In addition to the two hypothesized moderators, we coded potential moderators guided by use in previous meta-analyses of marketing and by additional suggestions from the anonymous expert reviewers of this research. For each independent sample, we coded data on study descriptors, sample descriptors, research design descriptors, effect size descriptors, and the moderators. In our analysis, we used the region in which the study took place and their average age as descriptors of the samples. In addition, we used information on the type of research (scenario, experiment, field study, survey) and a control variable for confounding factors as research design descriptors.

We also coded information on the personal responsibility for the sunk-cost decision, VHB-journal rankings, random assignment of study participants, attractiveness of the sunk-cost alternative, outcome effects, a confidence rating on estimation, gender and a dummy variable for flat rates in utilization decisions. Within this context, note that the preliminary analysis indicated that many of these factors were not significant predictors of effect size. Thus, even if we initially coded 
16 effect size moderators (see Appendix 1), the analyses focused on the seven effect size moderators listed in Tables 3 and 4.

Coding was conducted by two members of the meta-analysis research team. Coders were familiar with the research topic and the construct of interest. At the beginning of the coding, a first set of 17 articles was coded together to refine or, if necessary, adapt the coding rules of our protocol. We then coded the remaining 27 articles individually. However, whenever we were confronted with ambiguous or troublesome coding, we met to discuss and resolve the open questions. Many articles contain results from multiple experiments. We treated the data sets as statistically independent when a different subject pool was used for each experiment. In addition, some studies had multiple intervention groups because they used sunk costs to create multiple treatment levels. To avoid "double counts" of samples in our meta-analysis, we followed Higgins and Green's (2001) recommendation to combine groups to create single pairwise comparisons or to split the shared (control) group into multiple groups with smaller sample sizes. We chose the second approach only when the different manipulation levels of sunk costs were too extreme to reasonably integrate them into one treatment group. We then assumed that the multiple control groups had the same means and standard deviations as the original control group. This corresponds to Lipsey and Wilson's (2001) argumentation that possible dependencies between effect sizes for subsamples from the same study are assumed to be small, and standard practice has defined independence at the sample or study level.

For each independent sample, we needed to identify one group as the control and one group as the treatment group. Because sunk costs serve as the independent variable manipulated at different levels, we defined the zero- or low-sunk-cost-level group as the control group and the high-sunk-cost-level group as the treatment group. The dependent variable of the sunk-cost effect can be operationalized in multiple ways, depending on the respective decision type. In utilization decisions, individuals may use a higher sunk-cost alternative with a higher intensity or just choose to utilize the paid good or service despite other preferences or alternatives. In progress decisions, individuals may commit additional resources to an initially chosen alternative, report an increased probability to allocate funds, or simply choose to continue to invest.

After coding, we evaluated the categories with regard to their respective number of observations. Classes with only very few observations were collapsed to bigger ones. For region, we formed one category "North America" and one for "Other" which includes data that has been collected in the rest of the world. In a similar vein, we created a group for "Other" in type of research which includes everything else but the predominantly used scenario experiments. For non-categorical variables, such as age, the missing values were imputed by mean replacement. Imputations for categorical variables were performed by using portions of the attributes.

\subsection{Meta-analytic procedure}

Because most of our articles present results from experimental research, the effect size metric selected for the analysis is the standardized mean difference, as 
suggested by Lipsey and Wilson (2001). We use Cohen's $d$, which is the most widely used statistic in meta-analysis of experimental and intervention studies (Hunter and Schmidt 2004). This statistic focuses on between-group differences in experimental research and is suitable for contrasting two groups on dependent variables that are not operationalized in the same way. Effect sizes based on correlations, which are sometimes used in meta-analytic reviews, are especially recommended for estimating relationships in survey data (e.g., Fern and Monroe 1996).

We generated the effect size by calculating Cohen's $d$ with the means and standard deviations reported in the articles. If this information was not present, we estimated effect sizes from the exact $p$ values, or the test statistics, given likelihood ratios or correlations. For the computation, we used the online effect size calculator provided by Wilson (2013). The applied computation technique for each effect size appears in the Web Appendix (Sheet: Effect Size Calculation, column H). Before the single effect sizes can be integrated into a weighted mean, effect sizes need to be adjusted for small sample size bias. Because the standardized mean difference effect size suffers from a slight upward bias when based on small samples $(N<20)$, we calculated unbiased effect sizes on the basis of Lipsey and Wilson's (2001) work. After adjusting the effect sizes, we analyzed the effect size mean and its distribution. The integration of the standardized mean differences uses inverse variance weights to account for varying sample sizes in studies. We provide all data and values in the Web Appendix.

We performed the meta-analytic procedure of effect size integration using a mixed-effects model. We used a mixed-effects model because we assume that variance beyond sampling error is due to systematic and partly random factors. We use a multivariate weighted least squares regression (Lipsey and Wilson 2001) to model the systematic variance in effect sizes. In the regression, the $d$ values from a set of studies are regressed on the coded characteristics such as hypothesized effects or study characteristics. Those variables with statistically significant regression weights are considered to be moderators of the effect size (Hunter and Schmidt 2004). In addition, we calculated the analog to the analysis of variance (ANOVA) to gain further insights on how effect sizes depend on study-specific characteristics (Lipsey and Wilson 2001).

Both models separate the variability between effect sizes and the variance attributable to individual studies. They demand an estimate of the between-study variance. This random-effects variance component is estimated first and then entered into the analog to the ANOVA or weighted regression analysis. We used a method-of-moments estimation to estimate the random-effects variance component. As is multi-level meta-analysis [e.g., hierarchical linear models (HLM)], this is a powerful method, and both approaches lead to similar parameter estimates (Hox 2010). For the effects of time delay, region, and type of research, we used a multivariate dummy regression. The intercept serves as reference category and is indicated as base in Tables 3 and 4 .

To assess the overall fit of the regression model, we calculated $Q_{\text {Model }}$ and $Q_{\text {Residual }}$. $Q_{\text {Model }}$ is analogous to the $F$ test for the regression model, in which significance indicates that the regression model explains significant variability in the 
effect sizes. If $Q_{\text {Residual }}$ is significant, variability beyond subject-level sampling error remains across the effect sizes (Lipsey and Wilson 2001). To test individual regression coefficients for significance, we calculated a $z$ test. Using a similar procedure, we also conducted an analog to the ANOVA, which groups effect sizes in mutually exclusive categories on the basis of an independent variable. It tests the homogeneity among the effect sizes within the categories and also the differences between them. A significant between-category variance indicates that the mean effect sizes across groups differ more than sampling error (Lipsey and Wilson 2001). We conducted this analysis using the meta-analysis macros MetaReg.sps for the regression and MetaF.sps for the analog to the ANOVA for SPSS, provided online by Wilson (2010). The code is also available in Lipsey and Wilson (2001: 212-220). Finally, to address the file-drawer problem (Rosenthal 1979), we calculated the fail-safe $N$. The fail-safe $N$ estimates the number of studies reporting null results necessary to reduce the mean effect to a specified or criterion level $\left(\overline{\mathrm{ES}_{\mathrm{C}}}=0.2\right)$ (Lipsey and Wilson 2001). Because we selected the standardized mean difference effect size, we used the adaptation of Orwin (1983) and calculated the fail-safe $N$ with $k_{0}=k\left[\frac{\overline{\mathrm{ES}_{\mathrm{K}}}}{\overline{\mathrm{ES}_{\mathrm{C}}}}-1\right]$, where $k_{0}$ is the number of effect sizes needed to reduce the effect size to $\overline{\mathrm{ES}_{\mathrm{C}}}, k$ is the number of studies in the mean effect size, $\overline{\mathrm{ES}_{\mathrm{K}}}$ is the weighted mean effect size, and $\overline{\mathrm{ES}_{\mathrm{C}}}$ is the criterion effect size level (Lipsey and Wilson 2001: 166).

\section{Results}

\subsection{Average effect sizes and effect size heterogeneity}

Table 2 reports the results of the main effect, and Fig. 1 depicts the distributions of the effect sizes. On the basis of $k=100$ effect sizes, we find that the overall effect of sunk costs on decision-making has a moderate effect size $\left(\mathrm{ES}_{\mathrm{SM}}=0.496\right.$; $p<0.01$ ). This result is consistent with $\mathrm{H}_{1}$, that in the presence of sunk costs, decision-makers depart from the principles of economic decision-making and favor the sunk-cost alternative.

The results reveal significant heterogeneity in effect sizes $(Q=1,337.214$; $p<0.01$ ), indicating that there was statistically meaningful variability across the effect sizes. The heterogeneity in the effects suggests that other independent variables may account for the variability. For the derived decision types, we applied the analog to the ANOVA (Lipsey and Wilson 2001). For utilization decisions, we find an effect size $\left(\mathrm{ES}_{\mathrm{SM}}=0.581 ; p<0.01\right)$ that is slightly higher than the effect size for progress decisions $\left(\mathrm{ES}_{\mathrm{SM}}=0.443 ; p<0.01\right)$. The results provide support for both $\mathrm{H}_{2 \mathrm{a}}$ and $\mathrm{H}_{2 \mathrm{~b}}$. Despite some differences, we do not find a meaningful difference in the overall effect sizes between both types since the homogeneity test is not significant $(Q=0.954$; n.s.). 


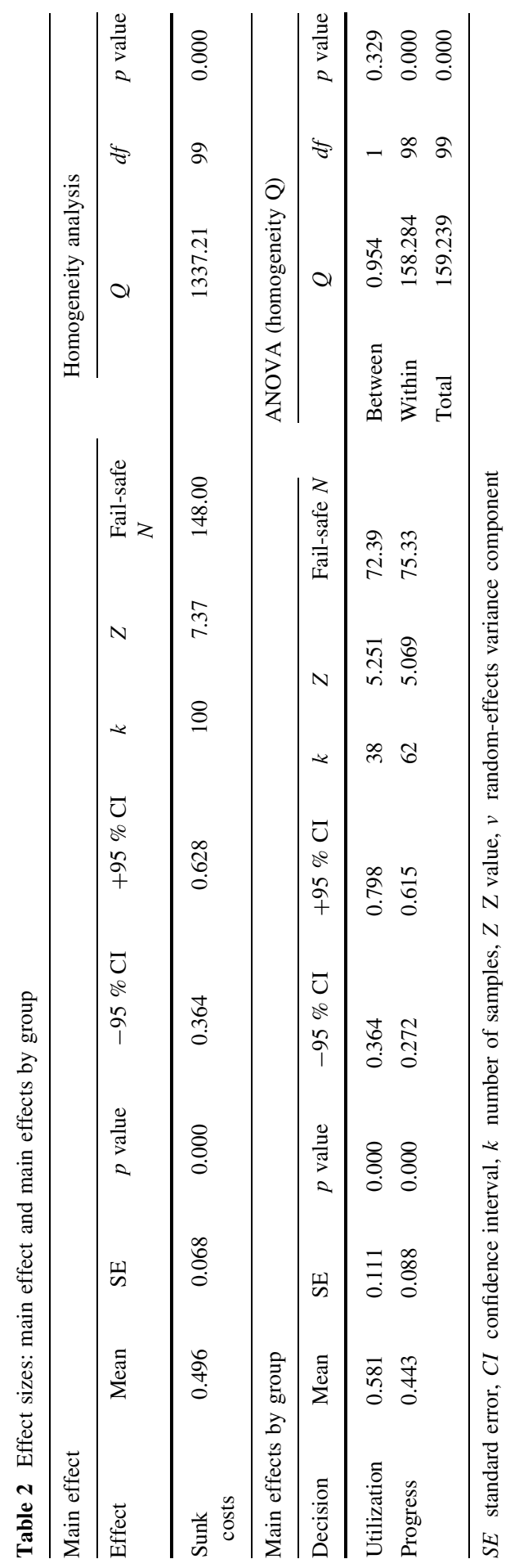




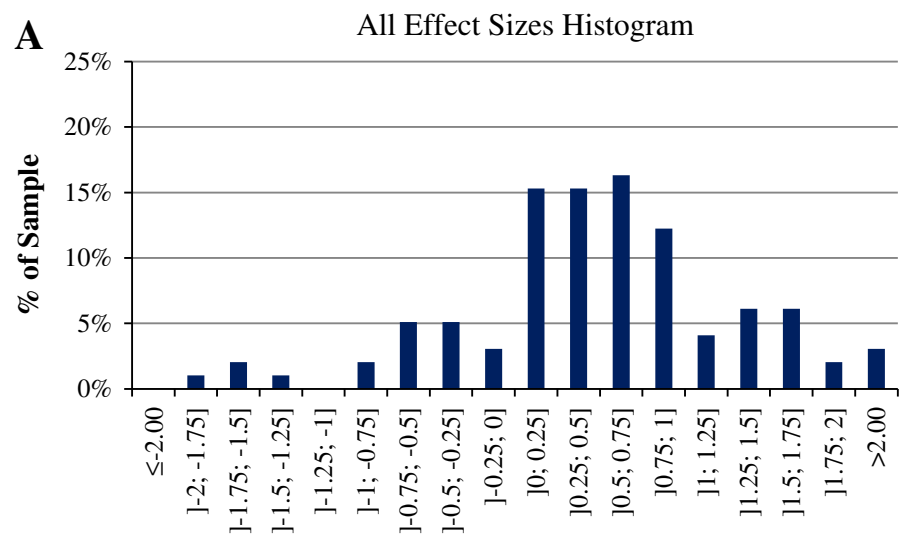

Effect Sizes

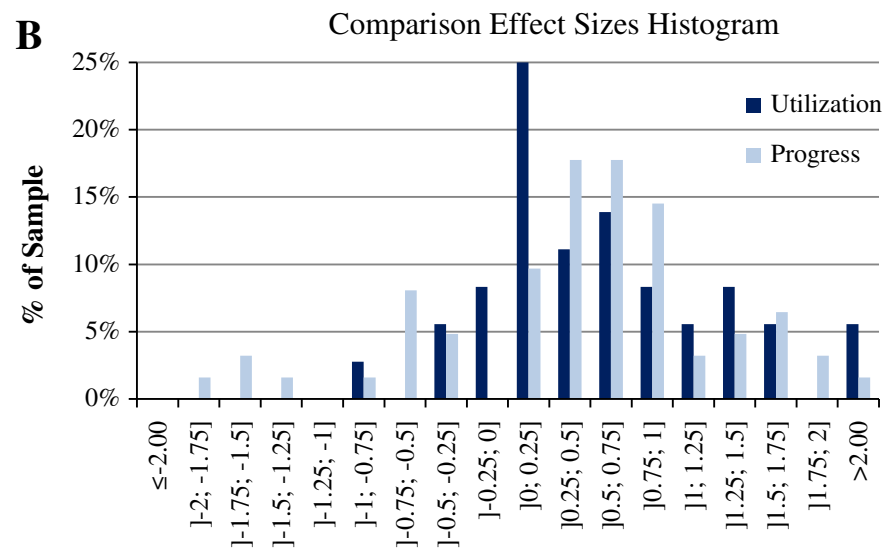

\section{Effect Sizes}

Fig. 1 Histograms of results

\subsection{Analysis of investigated moderators}

In our paper, we provide three different analyses. First, as it is the most common technique for meta-analytic reviews, we report the results of mixed-effects multivariate regression models to test how the analyzed moderators affect the observed effect sizes. In addition, we provide the results of an analog to the ANOVA model for the categorical variables to elaborate on the differences in effect sizes in Appendix 2 (Tables 9, 10). Lastly, we include separate univariate regressions to investigate the bivariate relationships between the analyzed moderators and effect sizes in Appendix 3 (Tables 11, 12). At this point, we split the presentation of our results with respect to the underlying decision type. First, we discuss our findings for utilization and thereafter for progress decisions. 
Regarding utilization decisions, the model estimates for the multivariate regressions are reported in Table 3. The raw mean effect size for the sunk-cost effect in utilization decisions is 0.569 and fairly high. The estimated model shows an appropriate overall model fit of $R^{2}=0.278$ and heterogeneity in effect sizes $(Q=17.442 ; p<0.05)$ showing that the regression model is significant.

The results of the ANOVA suggest that the sunk-cost effect is especially high when participants are not familiar with economic principles. Yet, when familiarity is high, the sunk-cost effect is only slightly weaker. A closer assessment of the regression model reveals that there is no significant decrease of effect sizes when people are highly familiar with microeconomic principles ( $\beta=0.04$; n.s.). Thus, we find no support for $\mathrm{H}_{3}$. However, with respect to $\mathrm{H}_{4 \mathrm{a}}$, we find that the time span between the initial and subsequent decision influences the effect. The impact of sunk costs is strongest shortly after the payment has been made. The standardized regression coefficients indicate the negative influence of time delay on the effect sizes of the sunk-cost effect. The sunk-cost effect decreases by $\beta=-0.342$ $(p<0.05)$ with a medium and by $\beta=-0.283(p<0.05)$ with a high time delay. We therefore find support for $\mathrm{H}_{4 \mathrm{a}}$, that the time delay between decisions serves as a significant moderator of the sunk-cost effect in utilization decisions. Apart from our hypothesized effects, we observe one additional significant effect. Specifically, we find that older subjects show a significantly smaller sunk-cost effect. Effect sizes decrease with age by $\beta=-0.339(p<0.05)$. In line with previous findings of Strough et al. (2008), our analysis thereby supports the idea that older adults are less subject to the sunk-cost fallacy than younger adults. Yet, we find no significant effects for the remaining covariates. Compared to studies that have been conducted in North America, studies from other regions of the world measure the same effect sizes $(\beta=0.032$; n.s.). The same holds true for the non-significant differences of students and other subjects $(\beta=0.206$; n.s. $)$, possible confounding factors $(\beta=-0.105$; n.s. $)$ as well as for different research designs $(\beta=0.188$; n.s. $)$.

Table 4 presents the results of our analysis for progress decisions. The mean effect size for the database is at a moderate level of 0.432 and the multivariate regression model is highly significant $(Q=20.979, p<0.01)$. The model fits the data satisfactorily $\left(R^{2}=0.271\right)$. As indicated in Table 4 , we found three significant effects which are summarized next.

In contrast to utilization decisions, we find that the sunk-cost effect is not weakened by a longer time delay between the initial and subsequent investments. The results show that the influence of sunk costs on decision-making is particularly high when the time delay between the initial and subsequent decision is very long. As the regression coefficient indicates, a high time delay has a reversed influence on the sunk-cost effect ( $\beta=0.421 ; p<0.05$ ). The results therefore provide support for $\mathrm{H}_{4 \mathrm{~b}}$ that the sunk-cost effect increases with time in a series of temporally separated but economically linked decisions. However, our findings do not provide support for hypothesis $\mathrm{H}_{3}$ that the sunk-cost effect is reduced by subjects' familiarity with rational economic decision-making $(\beta=-0.162$; n.s.). While controlling for factors without hypotheses, we find that the sunk-cost effect is weakened when confounding factors are not controlled for $(\beta=-0.273 ; p<0.1)$. In addition, we find that the effect sizes for non-student samples are lower $(\beta=-0.272$; 


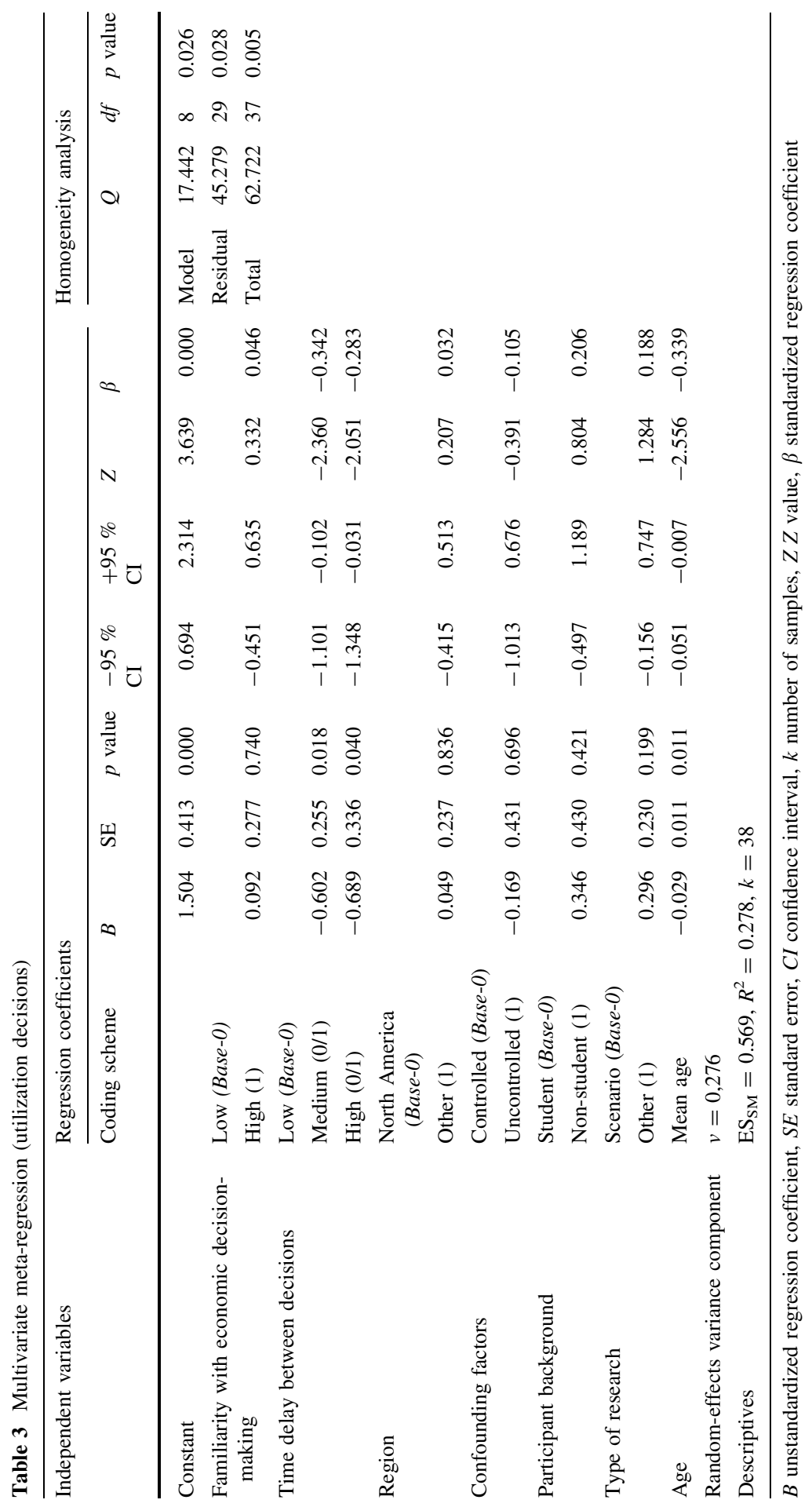




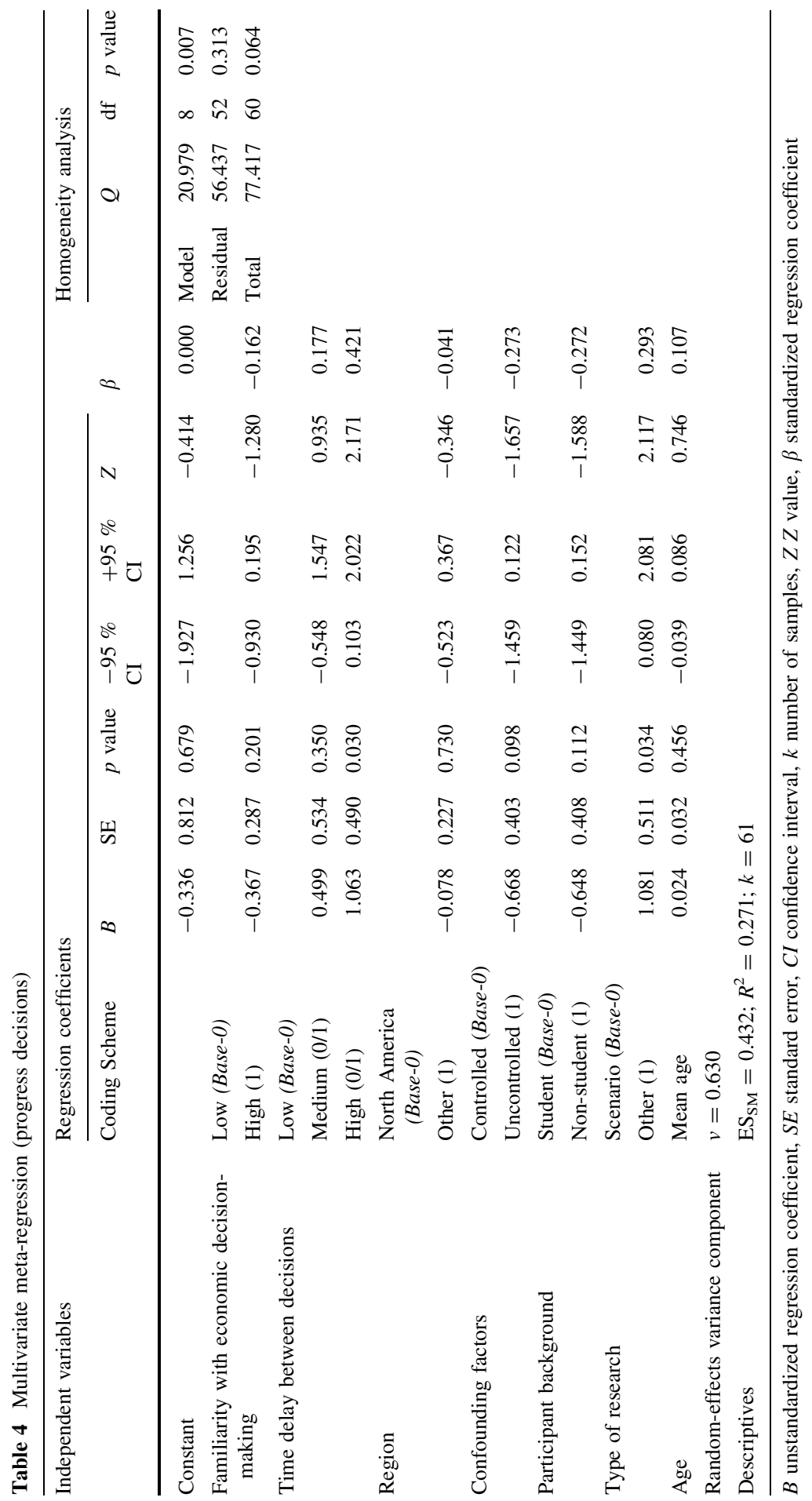


$p=0.112)$ than the effect sizes for student samples. Furthermore, the sunk-cost effect is stronger when studies are conducted as surveys or field-studies $(\beta=0.293$; $p<0.05)$ and not as scenario-based experiments. We do not find significant effects for the region where the study was conducted $(\beta=-0.041 ;$ n.s. $)$, or the participants' age $(\beta=0.107$; n.s.).

\section{General discussion}

This article presents the results of a meta-analytic review on studies that elaborate on the influence of sunk costs on economic decision-making. Overall, we find positive effect sizes for the sunk-cost effect, which leaves little doubt on its general existence. On the one hand, this finding lends support to the robustness of the sunkcost hypotheses as stated by Arkes and Blumer (1985). On the other hand, it runs counter to the findings of well-cited research on utilization decisions (Ashraf et al. 2010) and on progress decisions (Friedman et al. 2007). Yet we find that effect sizes deviate in reaction to our hypothesized moderators as well as for different sample and research design characteristics. Next, we discuss the findings with respect to the underlying decision situation, explicate the managerial consequences, provide topics for further research, and, finally, discuss the study's limitations.

\subsection{Conclusion}

Overall, we find clearly positive effect sizes for the sunk-cost effect in utilization decisions. Only very few studies indicate a reverse direction, whereas the majority of studies measure a weak-to-moderate positive influence of sunk costs on choices or usage intensity. However, according to the distribution of effect sizes (Fig. 1, Panel b) and the homogeneity analysis, the main effect measured in the studies is substantially heterogeneous.

With regard to our hypothesized moderators that influence the effect sizes, we find that the decision-maker's familiarity with economic decision-making does not seem to play an important role in utilization decisions. The studies that we analyzed assumed high familiarity when participants had a business background or were explicitly trained in economic decision-making. Yet, we find no significant support for the idea that knowing about basic microeconomic principles prevents individuals from falling prey to the sunk-cost effect. Apparently, individuals are not able to transfer the knowledge they obtain in their professional life to their everyday life. However, we find that the participants' age influences the sunk-cost effect. This supports findings from Strough et al. (2008) who also report that older adults are more likely than younger adults to make normatively correct decisions.

With respect to our second hypothesis, we find that the sunk-cost effect becomes smaller when the time between the first payment and the actual consumption decision increases. Therefore, we find support for the idea of payment depreciation (Gourville and Soman 1998; Prelec and Loewenstein 1998). With regard to utilization decisions which have most often been researched for day-to-day decisions, we find clear evidence that consumers indeed mentally forget about the 
"pain of paying" they felt when they purchased the product that would lead them to use it.

In addition, our results indicate that effect sizes are influenced by the type of research that has been conducted. We observe slightly different effect sizes for the predominantly used scenario experiments and other research designs. This may also help to explain why Ashraf et al. (2010: 2,386) "fail to find consistent evidence for sunk-cost effects." However, their conclusion that the sunk-cost effect does not exist may fall short. The smaller effect sizes found when the costs for the product are not explicitly emphasized in these field studies (e.g., different flat-rate prices) are not surprising because costs may be more salient in scenarios and other experimental settings. Moreover, Ashraf et al. (2010) used a storable product, which may also reduce the pressure for increased usage in response to sunk costs. Additional potential moderators, such as the region in which the study was conducted and the control of confounding factors does not seem to have noteworthy impacts on measured effect sizes.

With regard to progress decisions, we find that the effect sizes vary much more than those in utilization decisions. Nevertheless, most of them are still positive (Fig. 1, Panel b). Again, the heterogeneity in the data can partly be explained by our hypothesized effects.

We find a weak influence of participants' background in a way that studies based on student samples report slightly higher effect sizes. This is in line with the argument that we already raised for older adults in utilization decisions. Yet, we cannot find a significant impact of age on the sunk-cost effect in progress decisions. This may partly be explained by the fact that the multivariate regression analysis builds on a substantial number of imputed values. Moreover, we find a correlation between subjectś age and their background because most of the younger participants are business students. However, our non-significant results do not mean that these moderators do not affect the sunk-cost effect. Yet, within our study's sample sizes and statistical power, we are unable to document a statistically significant impact.

In addition, most studies use hypothetical scenarios. Unfortunately, the number of studies that base their findings on field or experimental data with economic consequences is limited. We have as little as $k=3$ samples of non-students with high familiarity in economic decision-making. Therefore, we are not able to separate these effects thoroughly. It would be desirable for further research not to use undergraduate students as research participants to draw conclusions regarding escalation tendencies in corporate decision-making.

Another noteworthy finding of our analysis is that the time delay between the initial and subsequent investments influences the effect sizes differently in progress than utilization decisions. We find that in progress decisions, effect sizes increase with time. Research must strictly distinguish between the effect of temporal and monetary sunk costs. However, we argue that in progress decisions, elapsed time can be considered an investment in a project. In addition, monetary resources are not invested at one point in time but continuously as the project progresses.

From a managerial perspective, research on the sunk-cost effect provides important insights into consumer behavior. Managers should take into account that the probability to make use of already-paid-for tickets decreases over time. This 
observation may have advantages and disadvantages, depending on the product or service sold. A service provider with limited capacities (e.g., health clubs, public pools) should consider selling many tickets in advance, to profit from payment depreciation effects. In contrast, service providers interested in a high usage rate (e.g., soccer stadiums, concerts) should make their customers aware of the "precious ticket" they are about to waste when they do not show up.

In progress decisions, companies should pay attention to long running projects and the managers' increasing tendency to stick to their initial decision as time goes by. In line with research on escalation of commitment, barriers can be implemented that activate a decision-maker's need to externally justify the project-related decisions or distribute responsibility to various decision-makers. As another example, companies can educate their employees to enhance decision quality. All these factors help reduce organizational inertia when confronted with escalation of commitment.

\subsection{Avenues for further research}

First, future research should further elaborate on the idea that participants background has an effect on the strength of the sunk-cost effect in progress decisions. Yet, although our results of the univariate regressions are very clear we only find a weak result in the multivariate analysis. To date, most research has used students to examine the influence of sunk costs and abstained from participants at higher age. However, the use of student samples may be a double-edged sword. In his second-order meta-analysis on the use of college students in social science research, Peterson (2001) finds that effect sizes based on student samples frequently differ from effect sizes based on non-students in both direction and magnitude. Therefore, further research should focus on well-educated, professional decisionmakers in a higher age rage. Otherwise, the effect sizes of the sunk-cost effect on escalation tendencies may be overestimated.

Second, factors constraining the sunk-cost effect must be investigated further. Consequences for decision-makers, their organizations, and their environment can be quite costly, especially in progress decisions for which sunk costs may foster escalation tendencies. Therefore, identification of constraining factors can assist organizations in implementing institutional barriers to prevent escalation. For example, the pressure to justify each decision externally may weaken escalation tendencies. Research on mental accounting budgets (Heath 1995; Heath and Soll 1996) and financial budgets (Tan and Yates 2002) demonstrates de-escalating commitment in response to sunk costs and may serve to direct additional research. With respect to mental budgets, research also should address the question of why exceeding budgets fosters de-escalation of commitment. Another constraining factor is opportunity costs. Although their impact on the sunk-cost effect in progress decisions is known to reduce escalation tendencies (Northcraft and Neale 1986), their impact on utilization decisions is still questionable. Despite this, information about opportunity costs is available in many everyday decisions. Cunha and Caldieraro (2009) show that the behavioral sunk-cost effect is a function of the ratio of the invested effort to the opportunity cost. Furthermore, extending these findings to the domain of monetary sunk costs would be particularly useful. 
Third, further research should elaborate the effect of time on progress decisions. To disentangle the influence of time and monetary investment decisions, studies should examine cases in which an investment is made at some time $t_{1}$ and then the decision to continue is made at some other time $t_{2}$, with little investment made between $t_{1}$ and $t_{2}$. The progress of time between subsequent progress decisions highlights another research avenue: It is possible that the occurrence of further projects or investment alternatives deteriorate the importance of the "old" project as well as the evaluation of the linked investments. In such cases, payment depreciation might also be observable in progress decisions.

Fourth, although research has assessed personal responsibility in progress decisions (e.g., Staw 1976; Schulz-Hardt et al. 2009), we are not aware of any studies that investigate the social context of a decision in utilization decisions. According to literature on sustainable consumption and green attitudes (e.g., Sheth et al. 2011; Urien and Kilbourne 2011), the responsibility for a purchased product may also reinforce the sunk-cost effect. Even Arkes and Blumer (1985) identify the motive "not to appear wasteful" as a potential reason behind the sunk-cost effect.

Fifth, the sunk-cost effect for utilization decisions was clearly observable. However, it remains unclear whether individuals are aware of this effect. Although the effect has a negative influence, in that individuals deviate from basic economic principles, it may also have a positive side. For example, an already-paid-for product may also serve as a pre-commitment device for consumers. Gourville and Soman (1998) track attendance of health-club members and find that attendance rate was highest right after the payment was made. Thus, it seems to matter whether consumers unconsciously or consciously use the sunk-cost effect to enhance goal pursuit by pre-committing to alternatives they would otherwise not use or consume. This case might be especially true for activities or services such as gyms or diets that require discipline and perseverance (DellaVigna and Malmendier 2006).

Sixth, in this research we treat usage intensity of flat-rate products as one type of utilization decision. However, these decision situations might differ when choices are between different alternatives. Therefore, we applied a separate dummy-coded meta-regression to account for that circumstance. Indeed, we find some indication that effect sizes for the sunk-cost effect under flat-rate usage are slightly lower. Yet our results are based on a small number of data sets $(k=6)$. Scant empirical research has explored the impact of sunk costs on flat-rate usage, which provides further research potential.

\subsection{Limitations}

Although the results of our meta-analysis integrate findings from several studies on the sunk-cost effect, thereby providing new insights into the strength of the effect and its moderators with respect to the underlying decision situation, the analysis also has shortcomings. First, a basic problem of every meta-analysis is that primary studies do not provide all the information needed to make the results perfectly comparable. This problem becomes especially evident when elaborating on the impact of the subject's age in progress decision for which the proportion of missing values is very high. In order to still be able to perform multivariate analyses data has 
been imputed which shifts the results for age to insignificance. In addition, the information in each study is subject to the coder's interpretation. For example, in our analysis the time delay between the initial and subsequent investments was coded high versus medium versus low. However, research might code a time delay as long for a $€ 20$ theater ticket purchased 4 weeks ago but code the same time delay of 4 weeks as short in the case of a $€ 1$ million business investment. Therefore, it is crucial to interpret the findings in accordance with our coding protocol provided in Appendix 1.

A second limitation of our study is that not all the studies we included are based on data sets collected with the same research design. Most studies use experimental data and examine the sunk-cost effect with hypothetical scenarios. However, we did not exclude data sets obtained from survey or field observations. The small number of cases made a separate analysis impossible. This reveals the problem of comparing effect sizes from different research designs. Therefore, we run our calculations with collapsed categories. In line with this, we did not separately analyze studies on progress decisions conducted with students versus corporate decision-makers. Although we find that participants' background affects the strength of the effect, we do not have a sufficient database to further elaborate on this issue.

A third limitation pertains to the impact of time on the effect sizes of the sunkcost effect in progress decisions. Although we only included studies that explicitly manipulate sunk costs, we are aware that our meta-analysis cannot disentangle the sunk-cost effect from other drivers of escalation tendencies. We attribute this to two reasons: first, funding can increase with project time, especially in scenario-based studies with multiple-linked progress decisions. Second, all studies analyzed involve monetary sunk costs, but we cannot rule out that other resources, such as time or effort, might also be invested as the project continues. We leave this issue for further research. Other than these shortcomings, our detailed discussion of sunkcost effects with respect to utilization and progress decisions offers fruitful insights for further academic discussion.

Open Access This article is distributed under the terms of the Creative Commons Attribution License which permits any use, distribution, and reproduction in any medium, provided the original author(s) and the source are credited.

\section{Appendix 1}

See Tables 5, 6, 7, 8 .

\section{Appendix 2}

See Tables 9 and 10.

\section{Appendix 3}

See Tables 11 and 12 . 
Table 5 Study descriptors

\begin{tabular}{|c|c|c|c|}
\hline $\begin{array}{l}\text { Variable } \\
\text { category }\end{array}$ & $\begin{array}{l}\text { Variable } \\
\text { specification }\end{array}$ & Coding & Coding description \\
\hline \multirow[t]{2}{*}{ Coding } & \multirow[t]{2}{*}{ n.a. } & Database & $\begin{array}{l}\text { Indicates from which database the respective study } \\
\text { was retrieved }[(\mathrm{BS})=\text { Business Source Premier, } \\
(\mathrm{EB})=\text { EconBiz, }(\mathrm{SD})=\text { Science Direct, } \\
(\mathrm{SL})=\text { Springer Link, }(\mathrm{SSRN})=\mathrm{SSRN}, \\
(\mathrm{WL})=\text { Wiley Online, (WI) = WISO, } \\
(\mathrm{CA})=\text { Citation Analysis]. The number behind the } \\
\text { two capital letters specifies the hit number when we } \\
\text { searched in the respective database }\end{array}$ \\
\hline & & Code & $\begin{array}{l}\text { Indicates the ID of the data point. This ID consists of } \\
\text { the year of publication, the first three letters of } \\
\text { author and study title, experiment number in the } \\
\text { study, and a letter }(\mathrm{A} / \mathrm{B} / \mathrm{C} / . . .)\end{array}$ \\
\hline \multirow[t]{7}{*}{ Paper } & \multirow[t]{7}{*}{ n.a. } & Authors & Name(s) of all author(s) \\
\hline & & Title & Title of the study \\
\hline & & Journal & Journal in which the study was published \\
\hline & & Year & Year of publication \\
\hline & & Volume & Volume of the journal \\
\hline & & Issue & Issue of the journal \\
\hline & & Pages & $\begin{array}{l}\text { Pages, on which the specific study can be found in } \\
\text { the respective journal }\end{array}$ \\
\hline $\begin{array}{l}\text { Type of } \\
\text { publication }\end{array}$ & n.a. & $\begin{array}{l}(1)=\text { Journal } \\
(2)=\text { Book } \\
\text { Chapter } \\
(3)=\text { Dissertation } \\
(4)=\text { Working } \\
\text { Paper } \\
(5)=\text { Book }\end{array}$ & $\begin{array}{l}\text { Captures whether the paper has appeared in an } \\
\text { academic journal, as a book chapter, in a } \\
\text { dissertation, as an unpublished working paper, or in } \\
\text { a book }\end{array}$ \\
\hline $\begin{array}{l}\text { Business- } \\
\text { related } \\
\text { outlet }\end{array}$ & n.a. & $\begin{array}{l}(0)=\mathrm{No} \\
(1)=\mathrm{Yes}\end{array}$ & $\begin{array}{l}\text { Captures whether the outlet of the published work is } \\
\text { related to business research. We define a work as } \\
\text { being related to business research when the title } \\
\text { indicates a business topic or the work is published } \\
\text { in a business-related journal (according to VHB- } \\
\text { ranking "Jourqual 2.1") or book series. If the work } \\
\text { is not published yet, the affiliation of the main } \\
\text { author is decisive }\end{array}$ \\
\hline $\begin{array}{l}\text { Outlet } \\
\text { ranking } \\
\text { (VHB) }\end{array}$ & n.a. & $\begin{array}{l}(1)=\mathrm{A} \\
(2)=\mathrm{B} \\
(3)=\mathrm{C} \\
(4)=\mathrm{D} \\
(5)=\mathrm{E} \\
(-99)=\text { n.a. }\end{array}$ & $\begin{array}{l}\text { Captures whether the empirical study is published in } \\
\text { an outlet that has high reputation, which is } \\
\text { operationalized by its ranking value. For the } \\
\text { purpose of this study, the VHB-ranking "Jourqual } \\
2.1 \text { " is employed. This ranks business-related } \\
\text { journals on the intervals (A-E), in which A } \\
\text { indicates the highest scientific quality. n.a. } \\
\text { indicates that this variable category is not } \\
\text { applicable to the respective study }\end{array}$ \\
\hline
\end{tabular}


Table 6 Sample descriptors

\begin{tabular}{|c|c|c|c|}
\hline $\begin{array}{l}\text { Variable } \\
\text { category }\end{array}$ & $\begin{array}{l}\text { Variable } \\
\text { specification }\end{array}$ & Coding & Coding description \\
\hline \multirow[t]{3}{*}{ Region } & North America & $\begin{array}{l}\text { (0) No } \\
\text { (1) Yes } \\
(-99) \text { n.a. }\end{array}$ & $\begin{array}{l}\text { We code region variables that indicate } \\
\text { the continent on which the data were } \\
\text { collected. That is, we note whether a } \\
\text { study is based on data from North }\end{array}$ \\
\hline & Europe & $\begin{array}{l}\text { (0) No } \\
\text { (1) Yes } \\
(-99) \text { n.a. }\end{array}$ & $\begin{array}{l}\text { America, Europe, or Africa, Asia, } \\
\text { South America, Oceania (= other) }\end{array}$ \\
\hline & Other & $\begin{array}{l}\text { (0) No } \\
\text { (1) Yes } \\
\text { (-99) n.a. }\end{array}$ & \\
\hline Sex & n.a. & $\begin{array}{l}(X)=\% \text { of females } \\
(-99)=\text { n.a. }\end{array}$ & Captures the gender of participants \\
\hline Age & n.a. & $\begin{array}{l}(X)=\text { Mean age } \\
\text { years } \\
(-99)=\text { n.a. } \\
(S D) \text { Age in years } \\
(-99)=\text { n.a. }\end{array}$ & $\begin{array}{l}\text { Captures the mean age and the age } \\
\text { standard deviations of participants }\end{array}$ \\
\hline $\begin{array}{l}\text { Participants' } \\
\text { Background }\end{array}$ & n.a. & $\begin{array}{l}(0)=\text { Students } \\
(1)=\text { Non-students } \\
(-99)=\text { n.a. }\end{array}$ & $\begin{array}{l}\text { Indicates whether the study is based on a } \\
\text { student sample or a non-student sample }\end{array}$ \\
\hline
\end{tabular}

Table 7 Research design descriptors

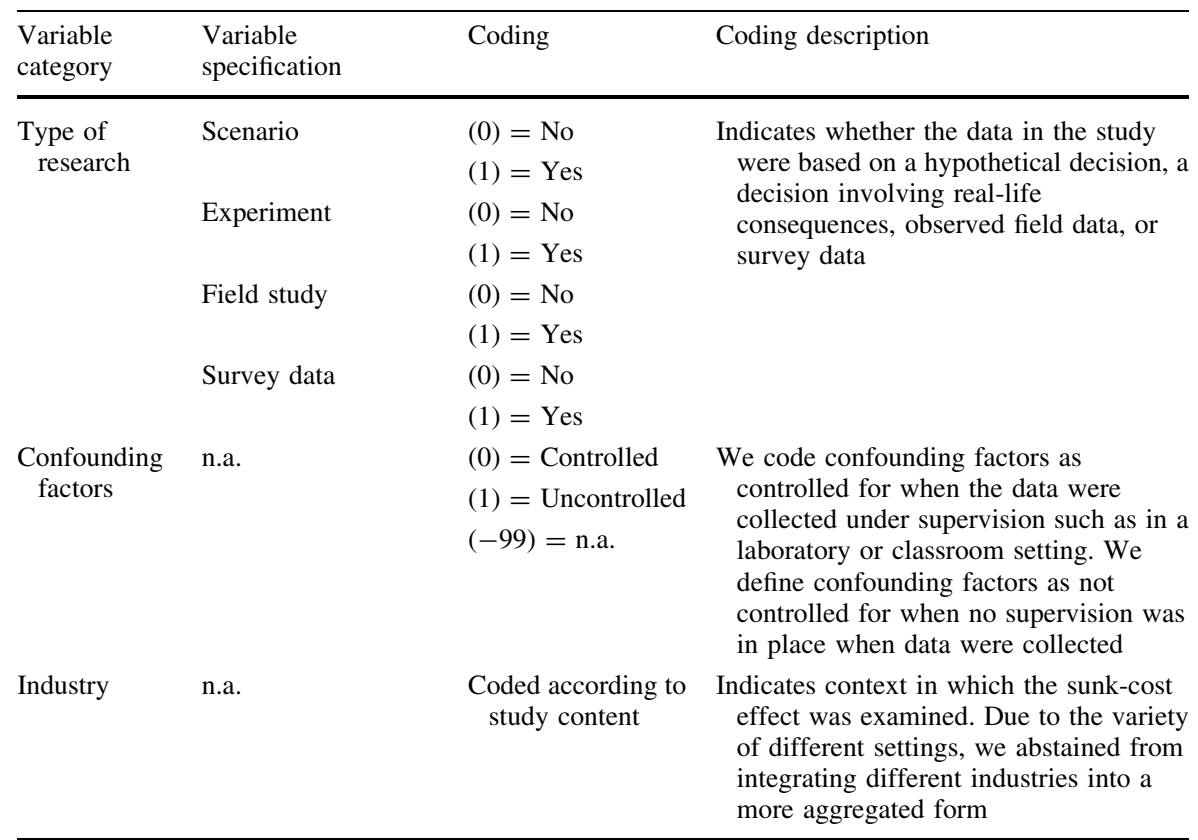


Table 7 continued

\begin{tabular}{|c|c|c|c|}
\hline $\begin{array}{l}\text { Variable } \\
\text { category }\end{array}$ & $\begin{array}{l}\text { Variable } \\
\text { specification }\end{array}$ & Coding & Coding description \\
\hline $\begin{array}{l}\text { Type of } \\
\text { assignment } \\
\text { to } \\
\text { conditions }\end{array}$ & n.a. & $\begin{array}{l}(1)=\text { Random } \\
\text { blocking } \\
(2)=\text { Random } \\
\text { simple } \\
(3)=\text { Non-random } \\
(-99)=\text { n.a. }\end{array}$ & $\begin{array}{l}\text { Indicates whether participants were } \\
\text { assigned, block random, simple random, } \\
\text { or not random to the sample groups }\end{array}$ \\
\hline Design & n.a. & $\begin{array}{l}(0)=\text { Within- } \\
\text { subjects } \\
(1)=\text { Between- } \\
\text { subjects } \\
(-99)=\text { n.a. }\end{array}$ & $\begin{array}{l}\text { Captures the research design of the } \\
\text { experimental settings }\end{array}$ \\
\hline $\begin{array}{l}\text { independent } \\
\text { variable }\end{array}$ & n.a. & $\begin{array}{l}\text { Object } \\
\text { Scale }\end{array}$ & $\begin{array}{l}\text { The level of sunk costs as object is } \\
\text { resumed from the respective study. No } \\
\text { aggregation is used }\end{array}$ \\
\hline $\begin{array}{l}\text { Dependent } \\
\text { variable }\end{array}$ & n.a. & $\begin{array}{l}\text { Object } \\
\text { Scale }\end{array}$ & $\begin{array}{l}\text { For resource utilization decisions, the } \\
\text { dependent variable is the result of a } \\
\text { choice and consequently a dichotomous } \\
\text { variable } \\
\text { In progress decisions, the dependent } \\
\text { variable is the result of a choice, the } \\
\text { likelihood to allocate additional funds, } \\
\text { or the amount of additionally invested } \\
\text { funds. No aggregation is used }\end{array}$ \\
\hline \multirow[t]{3}{*}{ Moderators } & Decision type & $\begin{array}{l}(0)=\text { Utilization } \\
\text { decision } \\
(1)=\text { Progress } \\
\text { decision }\end{array}$ & $\begin{array}{l}\text { Utilization decisions focus on the usage of } \\
\text { goods or services. In contrast, progress } \\
\text { decisions are determined by an initial } \\
\text { choice in a course of action and focus on } \\
\text { the continuation or abandonment of the } \\
\text { initially chosen course of action }\end{array}$ \\
\hline & $\begin{array}{l}\text { Attractiveness of } \\
\text { sunk-cost } \\
\text { alternative }\end{array}$ & $\begin{array}{l}(1)=\text { Low } \\
(2)=\text { Equal } \\
(3)=\text { Higher } \\
(-99)=\text { n.a. }\end{array}$ & $\begin{array}{l}\text { Indicates whether the sunk-cost alternative } \\
\text { is attractive in terms of estimated future } \\
\text { returns, opportunity costs, and/or } \\
\text { preference. This can refer to economic } \\
\text { issues and issues in the decision-makeŕs } \\
\text { personal life sphere }\end{array}$ \\
\hline & $\begin{array}{l}\text { Familiarity with } \\
\text { rational economic } \\
\text { decision-making }\end{array}$ & $\begin{array}{l}(0)=\text { Low } \\
(1)=\text { High } \\
(-99)=\text { n.a. }\end{array}$ & $\begin{array}{l}\text { We define undergraduate and graduate } \\
\text { business students and executives/ } \\
\text { managers as having high familiarity } \\
\text { with the decision context. All other } \\
\text { participants are defined as having low } \\
\text { familiarity with the decision context }\end{array}$ \\
\hline
\end{tabular}


Table 7 continued

\begin{tabular}{|c|c|c|c|}
\hline $\begin{array}{l}\text { Variable } \\
\text { category }\end{array}$ & $\begin{array}{l}\text { Variable } \\
\text { specification }\end{array}$ & Coding & Coding description \\
\hline & $\begin{array}{l}\text { Time delay } \\
\text { between } \\
\text { decisions }\end{array}$ & $\begin{array}{l}(0) /(1)=\text { Medium } \\
(0) /(1)=\text { High } \\
(-99)=\text { n.a. }\end{array}$ & $\begin{array}{l}\text { Captures the time difference between a first decision } \\
\text { to allocate funds in a course of action or good/ } \\
\text { service and the following progress or utilization } \\
\text { decision. When the temporal proximity between } \\
\text { the two decisions is high, it is coded as "low." In } \\
\text { contrast, key words such as "several weeks later, } \\
\text { days later..." are used as indicators for a temporal } \\
\text { delay between the decisions and are coded as } \\
\text { "medium." If there is no temporal proximity } \\
\text { between the decisions, it is coded as "high" }\end{array}$ \\
\hline & $\begin{array}{l}\text { Personal } \\
\text { responsible for } \\
\text { decision }\end{array}$ & $\begin{array}{l}(0)=\text { No } \\
(1)=\text { Yes } \\
(-99)=\text { n.a. }\end{array}$ & $\begin{array}{l}\text { Captures whether the decision-maker is responsible } \\
\text { for the decision that led to the appearance of sunk } \\
\text { costs }\end{array}$ \\
\hline & Outcome effects & $\begin{array}{l}(1)=\text { Participants } \\
(2)=\text { Others }\end{array}$ & $\begin{array}{l}\text { Captures whether participants' decision mainly has } \\
\text { an effect on their personal life sphere or on their } \\
\text { environment (e.g., decisions in a corporate } \\
\text { context, multi-group decisions.) }\end{array}$ \\
\hline
\end{tabular}

Table 8 Effect size descriptors

\begin{tabular}{|c|c|c|c|}
\hline Variable category & Variable specification & Coding & Coding description \\
\hline \multirow[t]{5}{*}{ Sample size } & \multirow[t]{5}{*}{ n.a. } & Total sample size & \multirow[t]{5}{*}{$\begin{array}{l}\text { Indicates the sizes of the } \\
\text { experimental groups }\end{array}$} \\
\hline & & Control group & \\
\hline & & Treatment group I & \\
\hline & & Treatment group II & \\
\hline & & Treatment group III & \\
\hline \multirow{12}{*}{$\begin{array}{l}\text { Dependent measure } \\
\text { descriptors }\end{array}$} & Regression coefficient & $(0)=$ No & \multirow{12}{*}{$\begin{array}{l}\text { Indicates the accessible } \\
\text { statistics of the } \\
\text { dependent measure for } \\
\text { each data point }\end{array}$} \\
\hline & & $(1)=$ Yes & \\
\hline & Means and standard & $(0)=$ No & \\
\hline & deviation & $(1)=$ Yes & \\
\hline & $T$ value or $F$ value & $(0)=$ No & \\
\hline & & $(1)=$ Yes & \\
\hline & Chi square & $(0)=\mathrm{No}$ & \\
\hline & & $(1)=$ Yes & \\
\hline & Proportions & $(0)=$ No & \\
\hline & (dichotomous) & $(1)=$ Yes & \\
\hline & Proportions & $(0)=$ No & \\
\hline & (polytomous) & $(1)=$ Yes & \\
\hline Page (effect size) & n.a. & Page of effect size & $\begin{array}{l}\text { Indicates the page on } \\
\text { which the dependent } \\
\text { measure descriptors can } \\
\text { be found in the work }\end{array}$ \\
\hline
\end{tabular}


Table 8 continued

\begin{tabular}{|c|c|c|c|}
\hline Variable category & Variable specification & Coding & Coding description \\
\hline \multirow[t]{4}{*}{$\begin{array}{l}\text { Means and standard } \\
\text { deviation }\end{array}$} & Control group & $\begin{array}{l}(X)=\text { Mean of control } \\
\text { group } \\
(-99)=\text { n.a. } \\
(X)=\text { SD of control } \\
\text { group } \\
(-99)=\text { n.a. }\end{array}$ & $\begin{array}{l}\text { Captures the means and } \\
\text { standard deviation of } \\
\text { the control and the } \\
\text { different treatment } \\
\text { groups if accessible }\end{array}$ \\
\hline & Treatment group I & $\begin{array}{l}(X)=\text { Mean of treatment } \\
\text { group I } \\
(-99)=\text { n.a. } \\
(X)=\text { SD of treatment } \\
\text { group I } \\
(-99)=\text { n.a. }\end{array}$ & \\
\hline & Treatment group II & $\begin{array}{l}(X)=\text { Mean of treatment } \\
\text { group II } \\
(-99)=\text { n.a. } \\
(X)=\text { SD of treatment } \\
\text { group II } \\
(-99)=\text { n.a. }\end{array}$ & \\
\hline & Treatment group III & $\begin{array}{l}(X)=\text { Mean of treatment } \\
\text { group III } \\
(-99)=\text { n.a. } \\
(X)=\text { SD of treatment } \\
\text { group III } \\
(-99)=\text { n.a. }\end{array}$ & \\
\hline \multirow[t]{3}{*}{$\begin{array}{l}\text { Frequencies and } \\
\text { proportions }\end{array}$} & Treatment group I & $\begin{array}{l}(X)=\text { Frequency } \\
\text { successful } \\
(-99)=\text { n.a. } \\
(X)=\text { Proportion } \\
\text { successful } \\
(-99)=\text { n.a. } \\
(X)=\text { Frequency } \\
\text { successful } \\
(-99)=\text { n.a. } \\
(X)=\text { Proportion } \\
\text { successful } \\
(-99)=\text { n.a. }\end{array}$ & $\begin{array}{l}\text { Captures the successful } \\
\text { frequencies and } \\
\text { proportions of the } \\
\text { control and the different } \\
\text { treatment groups if } \\
\text { accessible. We define } \\
\text { "successful" as the } \\
\text { proportion of } \\
\text { participants who fall } \\
\text { prey to the sunk-cost } \\
\text { effect }\end{array}$ \\
\hline & Treatment group II & $\begin{array}{l}(X)=\text { Frequency } \\
\text { successful } \\
(-99)=\text { n.a. } \\
(X)=\text { Proportion } \\
\text { successful } \\
(-99)=\text { n.a. }\end{array}$ & \\
\hline & Treatment group III & $\begin{array}{l}(X)=\text { Frequency } \\
\text { successful } \\
(-99)=\text { n.a. } \\
(X)=\text { Proportion } \\
\text { successful } \\
(-99)=\text { n.a. }\end{array}$ & \\
\hline
\end{tabular}


Table 8 continued

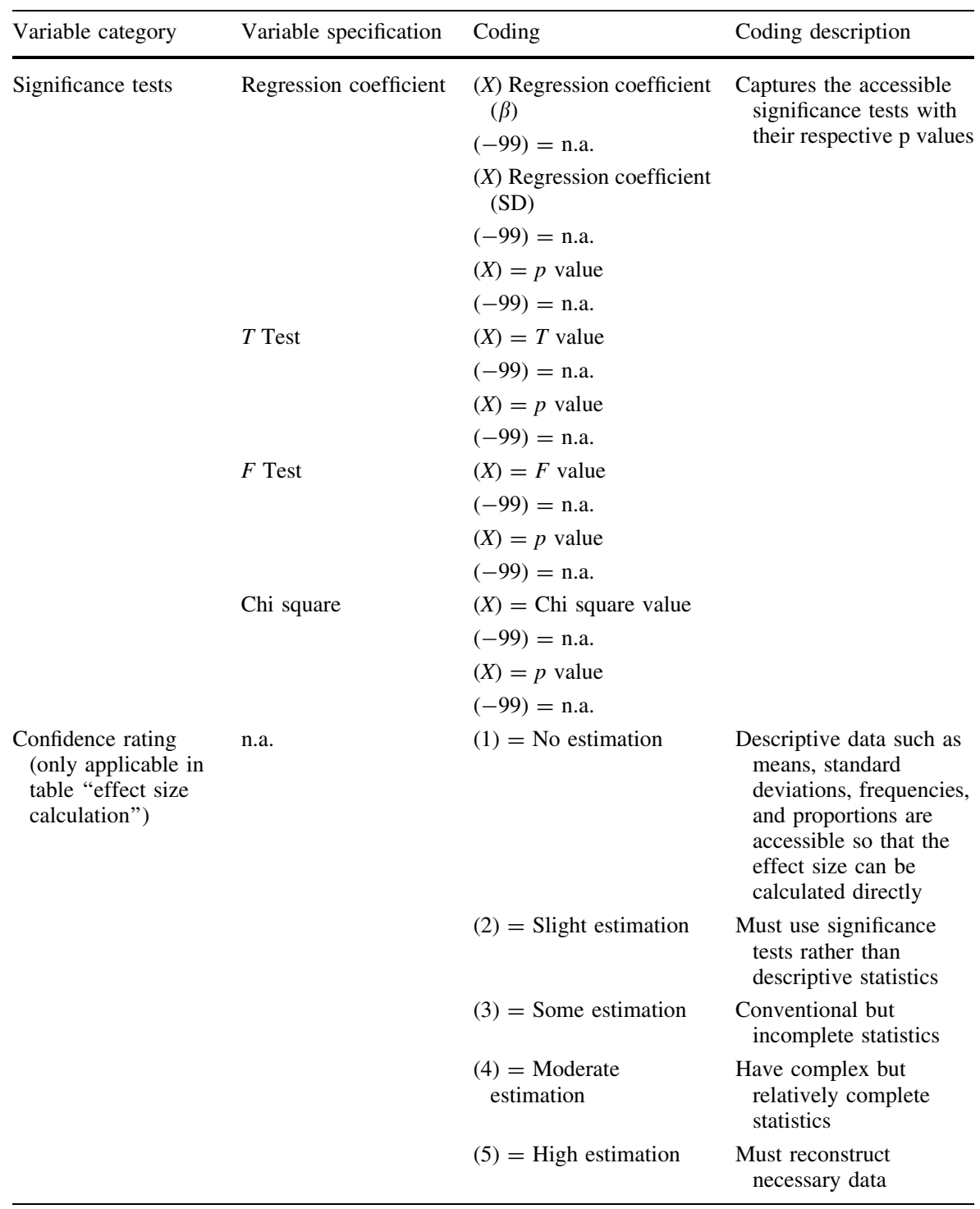




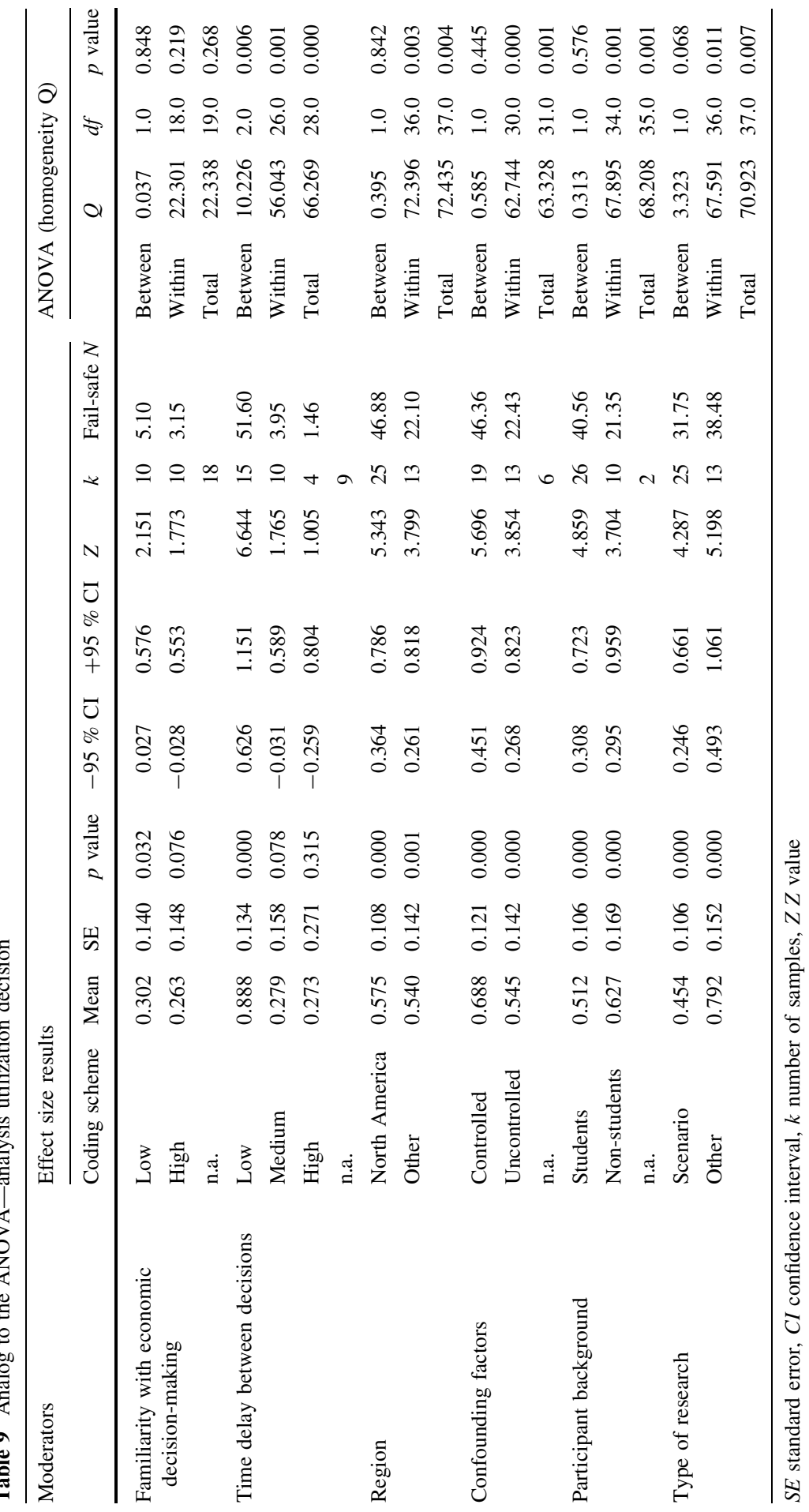




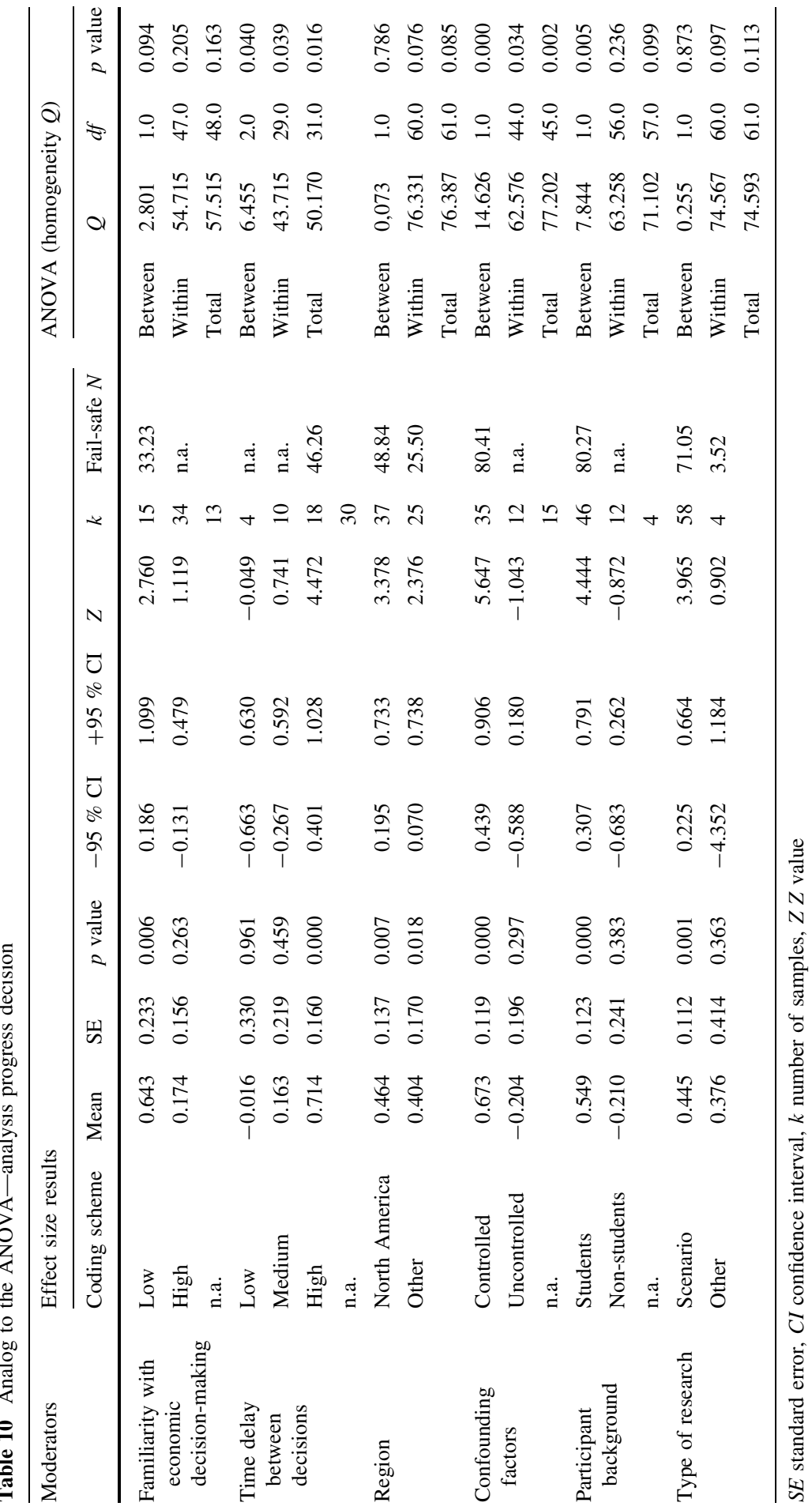




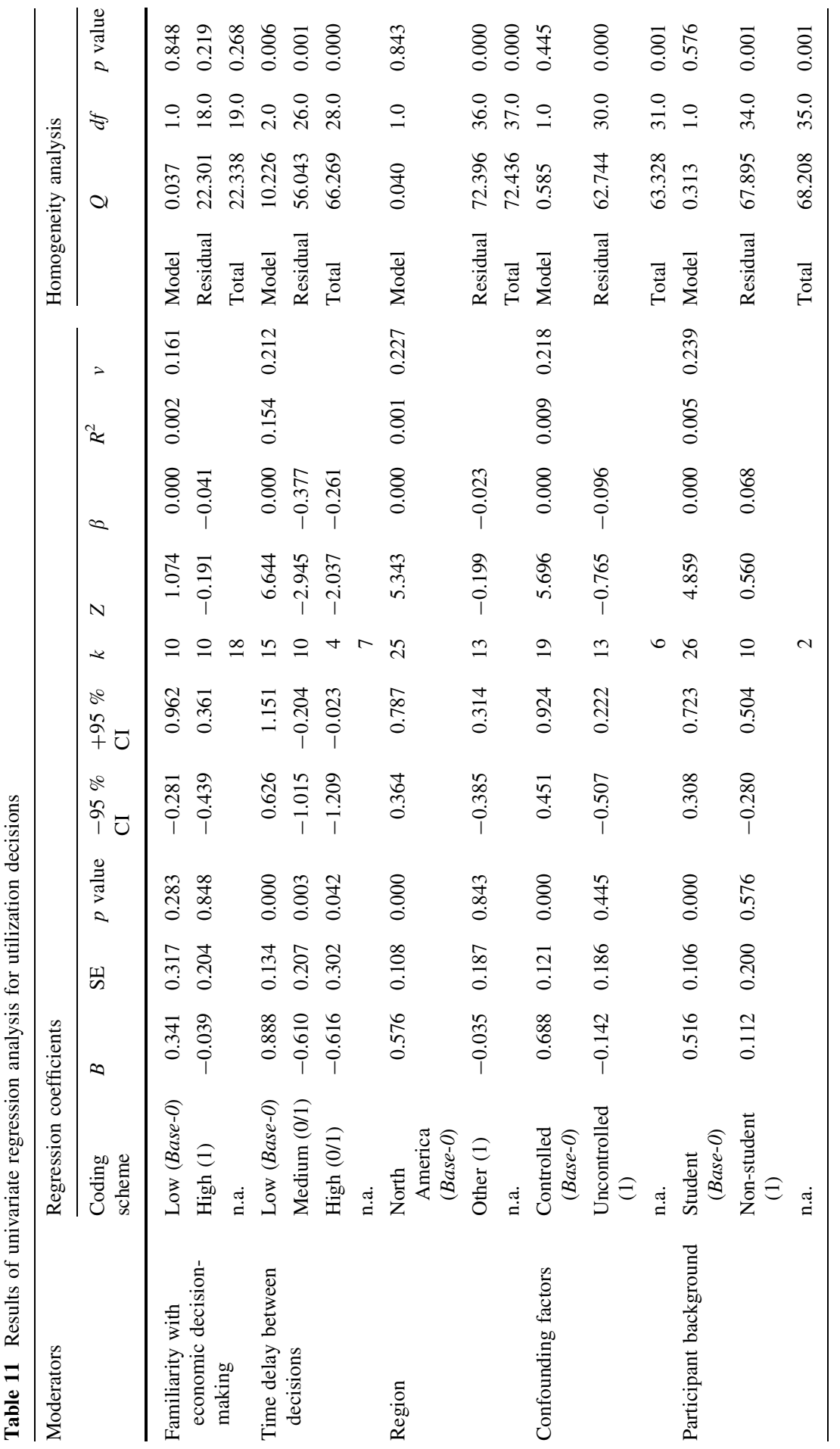




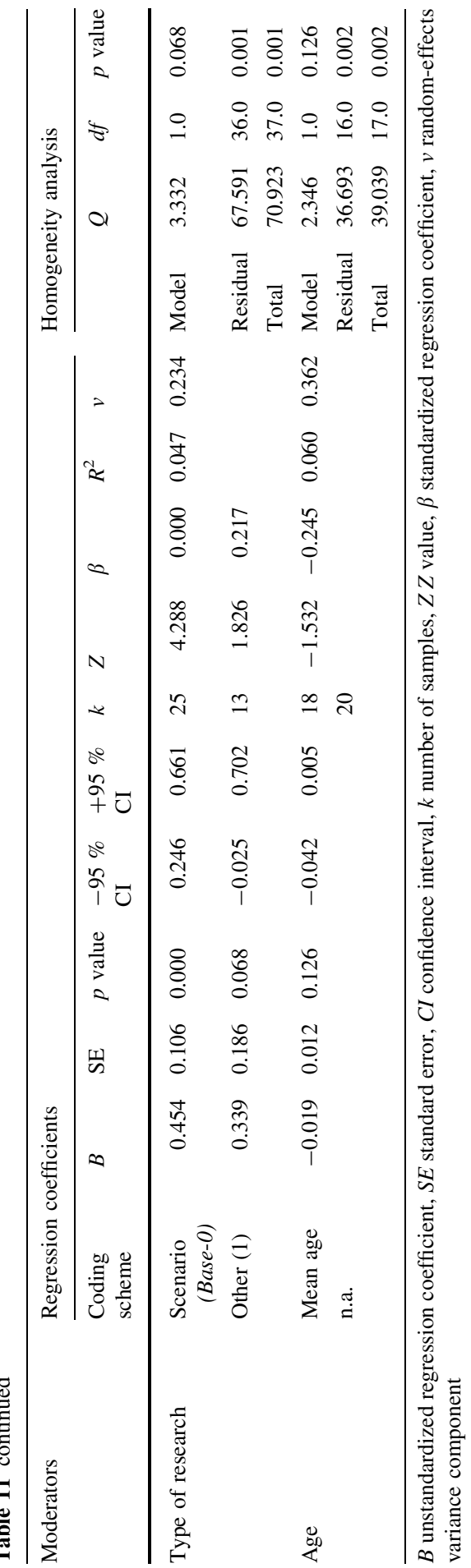




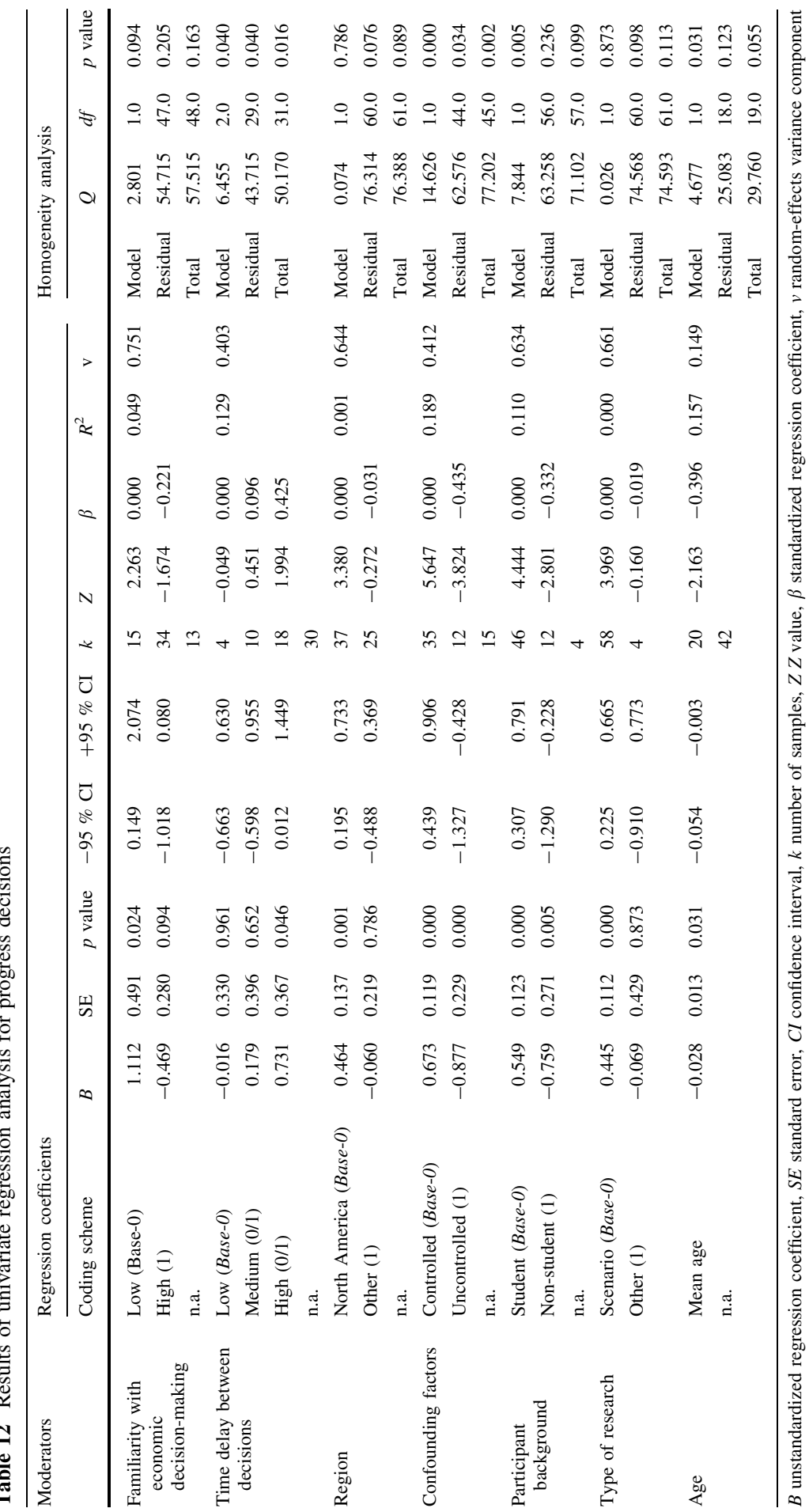




\section{References}

Anderson, J.R. 1981. Cognitive skills and their acquisition. Hillsdale: Psychology Press.

Anderson, J.R. 1982. Acquisition of cognitive skill. Psychological Review 89(4): 369-406.

Arkes, H.R., and P. Ayton. 1999. The sunk cost and concorde effects: are humans less rational than lower animals? Psychological Bulletin 125(5): 591-600.

Arkes, H.R., and C. Blumer. 1985. The psychology of sunk cost. Organizational Behavior and Human Decision Processes 35(1): 124-140.

Arkes, H.R., and L. Hutzel. 2000. The role of probability of success estimates in the sunk cost effect. Journal of Behavioral Decision Making 13(3): 295-306.

Armstrong, S.J., N. Coviello, and B. Safranek. 1993. Escalation bias: does it extend to marketing? Journal of the Academy of Marketing Science 21(3): 247-253.

Ashraf, N., J. Berry, and J.M. Shapiro. 2010. Can higher prices stimulate product use? Evidence from a field experiment in Zambia. American Economic Review 100(5): 2383-2413.

Astebro, T., S.A. Jeffrey, and G.K. Adomdza. 2007. Inventor perseverance after being told to quit: the role of cognitive biases. Journal of Behavioral Decision Making 20(3): 253-272.

Bazerman, M.H., T. Giuliano, and A. Appelman. 1984. Escalation of commitment in individual and group decision making. Organizational Behavior and Human Performance 33(2): 141-152.

Boehne, D.M., and P.W. Paese. 2000. Deciding whether to complete or terminate an unfinished project: a strong test of the project completion hypothesis. Organizational Behavior and Human Decision Processes 81(2): 178-194.

Brockner, J. 1992. The escalation of commitment to a failing course of action: toward theoretical progress. Academy of Management Review 17(1): 39-61.

Camerer, C.F., and R.A. Weber. 1999. The econometrics and behavioral economics of escalation of commitment: a re-examination of Staw and Hoang's NBA data. Journal of Economic Behavior \& Organization 39(1): 59-82.

Chase, W.G., and H.A. Simon. 1973. The mind́s eye in chess. In Visual information processing, ed. William G. Chase, 251-281. New York: Academic Press.

Conlon, D.E., and H. Garland. 1993. The role of project completion information in resource allocation decisions. Academy of Management Journal 36(2): 402-413.

Cunha Jr, M., and F. Caldieraro. 2009. Sunk-cost effects on purely behavioral investments. Cognitive Science 33(1): 105-113.

DellaVigna, S., and U. Malmendier. 2006. Paying not to go to the gym. American Economic Review 96(3): 694-719.

Dick, A.S., and K.R. Lord. 1998. The impact of membership fees on consumer attitude and choice. Psychology and Marketing 15(1): 41-58.

Ensley, Mica R. 2006. Expertise and situation awareness. In The Cambridge handbook of expertise and expert performance, eds. K. Anders Ericsson, Neil Charness, Robert R. Hoffman, and Paul J. Feltovich, 633-651. Cambridge: Cambridge University Press.

Feltovich, Paul J., Michael J. Prietula, and K. Anders Ericsson. 2006. Studies of expertise from psychological perspectives. In The Cambridge handbook of expertise and expert performance, eds. K. Anders Ericsson, Neil Charness, Robert R. Hoffman, and Paul J. Feltovich, 14-68. Cambridge: Cambridge University Press.

Fennema, M.G., and J.D. Perkins. 2008. Mental budgeting versus marginal decision making: training, experience, and justification effects on decisions involving sunk costs. Journal of Behavioral Decision Making 21(3): 225-239.

Fern, E.F., and K.B. Monroe. 1996. Effect size estimates: issues and problems in interpretation. Journal of Consumer Research 23(2): 89-105.

Festinger, L. 1957. A theory of cognitive dissonance. Stanford: Stanford University Press.

Frey, B.S., and R. Eichenberger. 1996. Marriage paradoxes. Rationality and Society 8(2): 187-206.

Friedman, D., K. Pommerenke, R. Lukose, G. Milam, and B.A. Huberman. 2007. Searching for the sunk cost fallacy. Experimental Economics 10(1): 79-104.

Garland, H. 1990. Throwing good money after bad: the effect of sunk costs on the decision to escalate commitment to an ongoing project. Journal of Applied Psychology 75(6): 728-731.

Garland, H., and D.E. Conlon. 1998. Too close to quit: the role of project completion in maintaining commitment. Journal of Applied Social Psychology 28(22): 2025-2048. 
Garland, H., and S. Newport. 1991. Effects of absolute and relative sunk costs on the decision to persist with a course of action. Organizational Behavior and Human Decision Processes 48(1): 55-69.

Garland, H., C.A. Sandefur, and A.C. Rogers. 1990. De-escalation of commitment in oil exploration: when sunk costs and negative feedback coincide. Journal of Applied Psychology 75(6): 721-727.

Gino, F. 2008. Do we listen to advice just because we paid for it? The impact of advice cost on its use. Organizational Behavior and Human Decision Processes 107(2): 234-345.

Gourville, J.T., and D. Soman. 1998. Payment depreciation: the behavioral effects of temporally separating payments from consumption. Journal of Consumer Research 25(2): 160-174.

Greitemeyer, T., S. Schulz-Hardt, G. Popien, and D. Frey. 2005. Der Einfluss versunkener monetärer und zeitlicher Kosten auf Ressourcenallokationen. Zeitschrift für Arbeits- und Organisationspsychologie 49(1): 35-43.

Guler, I. 2007. Throwing good money after bad? Political and institutional influences on sequential decision making in the venture capital industry. Administrative Science Quarterly 52(2): 248-285.

Heath, C. 1995. Escalation and de-escalation of commitment in response to sunk costs: the role of budgeting in mental accounting. Organizational Behavior and Human Decision Processes 62(1): 38-54.

Heath, C., and J.B. Soll. 1996. Mental budgeting and consumer decisions. Journal of Consumer Research 23(1): 40-52.

Higgins, J.P.T and S. Green. 2001. Cochrane handbook for systematic reviews of interventions, accessed online at: http://handbook.cochrane.org/front_page.htm. Access date 11 Sep 2013.

Hox, J.J. 2010. Multilevel analysis, 2nd ed. New York: Routledge.

Hunter, J.E., and F.L. Schmidt. 2004. Methods of meta-analysis, 2nd ed. Thousand Oaks: Sage Publications.

Jang, D., A.S. Mattila, and B. Bai. 2007. Restaurant membership fee and customer choice: the effects of sunk cost and feelings of regret. International Journal of Hospitality Management 26(3): 687-697.

Janssen, M.A., T.A. Kohler, and M. Scheffer. 2003. Sunk-cost effects and vulnerability to collapse in ancient Societies. Current Anthropology 44(5): 722-728.

Jensen, J.M., D.E. Conlon, S.E. Humphrey, and H. Moon. 2011. The consequences of completion: how level of completion influences information concealment by decision makers. Journal of Applied Social Psychology 41(2): 401-428.

Just, D.R., and B. Wansink. 2011. The flat-rate pricing paradox: conflicting effects of "all-you-can-eat" buffet pricing. Review of Economics and Statistics 93(1): 193-200.

Kahneman, D., and A. Tversky. 1979. Prospect theory: an analysis of decision under risk. Econometrica 47(2): 263-291.

Keil, M., A. Rai, and J. Mann. 2000. Why software projects escalate: an empirical analysis and test of four theoretical models. MIS Quarterly 24(4): 631-664.

Larkin, J., J. McDermott, D.P. Simon, and H.A. Simon. 1980. Expert and novice performance in solving physics problems. Science 208(4450): 1335-1342.

Lipsey, M.W., and D.B. Wilson. 2001. Practical meta-analysis. Thousand Oaks: Sage Publications.

Macaskill, A.C., and T.D. Hackenberg. 2012. The sunk cost effect in pigeons and humans: some determinants of decisions about persistance. Journal of the Experimental Analysis of Behavior 97(1): 85-100.

Maestripieri, D., and E. Alleva. 1991. Litter defence and parental investment allocation in house mice. Behavioural Processes 23(3): 223-230.

Manez, J., M.E. R-B, A. Sanchis, and J.A. Sanchis. 2009. The role of sunk costs in the decision to invest in R\&D. Journal of Industrial Economics 57(4): 712-735.

Moon, H. 2001. Looking forward and looking back: integrating completion and sunk cost effects within an escalation-of-commitment progress decision. Journal of Applied Psychology 86(1): 104-113.

Navarro, A.D., and E. Fantino. 2005. The sunk cost effect in pigeons and humans. Journal of the Experimental Analysis of Behavior 83(1): 1-13.

Navarro, A.D., and E. Fantino. 2009. The sunk-time effect: an exploration. Journal of Behavioral Decision Making 22(3): 252-270.

Northcraft, G.B., and M.A. Neale. 1986. Opportunity costs and the framing of resource allocation decisions. Organizational Behavior and Human Decision Processes 37(3): 348-356.

Orwin, R.G. 1983. A fail-safe N for effect size in meta-analysis. Journal of Educational and Behavioral Statistics 8(2): 157-159.

Otto, A.R. 2010. Three attempts to replicate the behavioral sunk-cost effect: a note on Cunha and Caldieraro (2009). Cognitive Science 34(8): 1379-1383.

Peterson, R.A. 2001. On the use of college students in social science research: insights from a secondorder meta-analysis. Journal of Consumer Research 28(3): 450-461. 
Prelec, D., and G. Loewenstein. 1998. The red and the black: mental accounting of savings and debt. Marketing Science 17(1): 4-28.

Robbert, T. 2013. Dienstleistungstarife und Nutzungsentscheidungen. Wiesbaden: Springer.

Rosenbaum, D.I., and F. Lamort. 1992. Entry, barriers, exit, and sunk costs: an analysis. Applied Economics 24(3): 297-304.

Rosenthal, R. 1979. The "file drawer problem" and tolerance for null results. Psychological Bulletin 86(3): 638-641.

Schaubroeck, J., and E. Davis. 1994. Prospect theory predictions when escalation is not the only chance to recover sunk costs. Organizational Behavior and Human Processes 57(1): 59-82.

Schulz-Hardt, S., B. Thurow-Kröning, and D. Frey. 2009. Preference-based escalation: a new interpretation for the responsibility effect in escalating commitment and entrapment. Organizational Behavior and Human Decision Processes 108(2): 175-186.

Sheth, J.N., N.K. Sethia, and S. Srinivas. 2011. Mindful consumption: a customer-centric approach to sustainability. Journal of the Academy of Marketing Science 39(1): 21-39.

Shin, D. 2008. Information acquisition and optimal project management. International Journal of Industrial Organization 26(4): 1032-1043.

Simester, D., and J. Zhang. 2010. Why are bad products so hard to kill? Management Science 56(7): 1161-1179.

Sleesman, D.J., D.E. Conlon, G. McNamara, and J.E. Miles. 2012. Cleaning up the big muddy: a metaanalytic review of the determinants of escalation of commitment. Academy of Management Journal 55(3): 541-562.

Soman, D. 2001. The mental accounting of sunk time costs: why time is not like money. Journal of Behavioral Decision Making 14(3): 169-185.

Soman, D. 2003. The effect of payment transparency on consumption: quasi-experiments from the field. Marketing Letters 14(3): 173-183.

Soman, D., and A. Cheema. 2001. The effect of windfall gains on the sunk-cost effect. Marketing Letters 12(1): 51-63.

Soman, D., and J.T. Gourville. 2001. Transaction decoupling: how price bundling affects the decision to consume. Journal of Marketing Research 38(1): 30-44.

Staw, B.M. 1976. Knee-deep in the big muddy : a study of escalating commitment to a chosen course of action. Organizational Behavior and Human Performance 16(1): 27-44.

Staw, B.M. 1981. The escalation of commitment to a course of action. Academy of Management Review 6(4): 577-587.

Staw, B.M., and F.V. Fox. 1977. Escalation: the determinants of commitment to a chosen course of action. Human Relations 30(5): 431-450.

Staw, B.M., and H. Hoang. 1995. Sunk costs in the NBA: why draft order affects playing time and survival in professional basketball. Administrative Science Quarterly 40(3): 474-494.

Staw, B.M., and J. Ross. 1989. Understanding behavior in escalation situations. Science 246(4927): $216-220$.

Strough, J.N., C.M. Mehta, J.P. McFall, and K.L. Schuller. 2008. Are older adults less subject to the sunkcost fallacy than younger adults? Psychological Science 19(7): 650-652.

Tan, H.-T., and J.F. Yates. 1995. Sunk cost effects: the influences of instruction and future return estimates. Organizational Behavior and Human Decision Processes 63(3): 311-319.

Tan, H.-T., and J.F. Yates. 2002. Financial budgets and escalation effects. Organizational Behavior and Human Decision Processes 87(2): 300-322.

Thaler, R. 1980. Toward a positive theory of consumer choice. Journal of Economic Behavior \& Organization 1(1): 39-60.

Thaler, R. 1985. Mental accounting and consumer choice. Marketing Science 4(3): 199-214.

Thaler, R.H. 1999. Mental accounting matters. Journal of Behavioral Decision Making 12(3): 183-206.

Urien, B., and W. Kilbourne. 2011. Generativity and self-enhancement values in eco-friendly behavioral intentions and environmentally responsible consumption behavior. Psychology \& Marketing 28(1): 69-90.

Vetter, J., A. Benlian, and T. Hess. 2012. Zur Rolle versunkener Kosten in aufeinander folgenden ITOutsourcing-Entscheidungen. Zeitschrift für Betriebswirtschaft 82(2): 181-213.

Wilson, D.B. 2010. Meta-analysis stuff, accessed online at: http://mason.gmu.edu/ dwilsonb/ma.html.Fairfax.

Wilson, D.B. 2013. Practical meta-analysis effect size calculator, accessed online at: http://cebcp.org/ practical-meta-analysis-effect-size-calculator/.

Wong, K.F.E., and J.Y.Y. Kwong. 2007. The role of anticipated regret in escalation of commitment. Journal of Applied Psychology 92(2): 545-555.

Zayer, E. 2007. Verspätete Projektabbrüche in F\&E. Wiesbaden: Springer. 